\title{
A review on occupant behavior in urban building energy models
}

\section{Journal Article}

Author(s):

Happle, Gabriel (1); Fonseca, Jimeno A.; Schlueter, Arno

Publication date:

2018-09-01

Permanent link:

https://doi.org/10.3929/ethz-b-000278803

\section{Rights / license:}

Creative Commons Attribution-NonCommercial-NoDerivatives 4.0 International

\section{Originally published in:}

Energy and Buildings 174, https://doi.org/10.1016/j.enbuild.2018.06.030 


\title{
A review on occupant behavior in urban building energy models
}

\author{
Gabriel Happle $e^{\mathrm{a}, \mathrm{b}}$, Jimeno A. Fonseca ${ }^{\mathrm{a}, \mathrm{b}}$, Arno Schlueter ${ }^{\mathrm{a}, \mathrm{b}}$ \\ ${ }^{a}$ Future Cities Laboratory, Singapore-ETH Centre, 1 Create Way, CREATE Tower, Singapore 138602 \\ ${ }^{b}$ Architecture and Building Systems, Institute of Technology in Architecture, ETH Zurich, Stefano-Franscini-Platz 1, CH-8093 Zurich, Switzerland
}

This document is the accepted manuscript version of the following article:

Authors: Gabriel Happle, Jimeno A. Fonseca and Arno Schlueter (2018)

Title: A review on occupant behavior in urban building energy models

Journal: Energy and Buildings, vol. 174, pp. 276-292.

Publisher: Elsevier

DOI: $10.1016 /$ j.enbuild.2018.06.030

This manuscript version is made available under the CC-BY-NC-ND 4.0 license

Originally uploaded to URL: https://github.com/gabriel-happle/publications on 2020-03-12

\begin{abstract}
Urban building energy models aspire to become key planning tools for the holistic optimization of buildings, urban design, and energy systems in neighborhoods and districts. The energy demand of buildings is largely influenced by the behavior of the occupants. The insufficient consideration of occupant behavior is one of the causes to the "performance gap" in buildings - the difference between the simulated and the actually observed energy consumption. On the urban-scale impacts of different occupant behavior modeling approaches onto the various purposes of urban building energy models are still largely unknown. Research shows that the inappropriate choice of occupant behavior model could result in oversized district energy systems, leading to over-investment and low operational efficiency. This work therefore reviews urban building energy models in terms of their occupant behavior modeling approaches. Three categories of approaches are established and discussed: (1) deterministic space-based approaches, (2) stochastic space-based approaches, and (3) stochastic person-based approaches. They are further assessed in terms of their strategy to consider diversity in occupant behavior. Stochastic models, especially stochastic person-based models, seem to be superior to deterministic models. However, there are no stochastic models available yet that can be used for case studies of mixed-districts, comprising buildings of various occupancy types. In the reviewed urban-scale approaches, only single-use residential or office districts are modeled with stochastic techniques. However, people interact with various buildings on a daily basis. Their activities relate to their presence in different spaces at the urban-scale and to their use of appliances in those spaces. Their individual levels of comfort and behavioral patterns govern the control actions towards building systems. Therefore, a novel activity-based multi-agent approach for urban occupant behavior modeling is proposed as alternative to current approaches.
\end{abstract}

Keywords: urban building energy model, energy-related occupant behavior, occupancy, occupant behavior model

\section{Introduction}

Urban areas house more than half of the global population and cities are responsible for more than $70 \%$ of the global carbon dioxide emissions. At the same time, cities are crucial actors in the transition towards sustainable energy

Email address: happle@arch.ethz.ch (Gabriel Happle) 
supply [1]. Urban districts and communities play an important role in the implementation of building energy efficiency policies and low-carbon energy supply and distribution systems [2]. The extent of required information on the building stock status, however, makes it difficult to obtain useful data about energy consumption in buildings. Time consuming monitoring campaigns to collect measured data of high granularity, suitable for scenario analysis or the evaluation of policies, are often infeasible [3]. Urban-scale building energy modeling aims to tackle this challenge by generating the required data via simulation.

\subsection{From building-scale to urban-scale energy models}

Urban-scale modeling tools are becoming increasingly available. They are expected to become a key planning tool to seek the most effective energy policies and strategies at the neighborhood, district and city levels [3, 4, 5]. Bottom-up physics-based engineering [6, 7, 8, 9] urban building energy models (UBEM) [4] forecast the performance of several dozens to thousands of buildings. The approach of UBEM is to apply physical models of heat and mass flow in and around buildings to predict operational energy uses as well as indoor and outdoor environmental conditions for groups of buildings [4]. Bottom-up engineering UBEMs are more versatile than statistical models, and allow planners to quantitatively assess retrofit strategies and energy supply options [10]. Integrated with urban form generation such models can be used in an early stage of planning for energy-driven urban design [11]. This is a concept that uses urban design parameters, such as density and land use (building occupancy types) to achieve a better performance of the district energy systems.

For this type of models, typically building-scale methods and models are directly scaled up to multiple buildings with little or no modifications. However, the switch from building-scale to district-scale is not just the simple aggregation of buildings due to the complex interactions within the urban fabric [12]. Physical properties such as building design, district layout and the local microclimate influence the energy demand of a district as well as occupancy-related properties like building indoor conditions and socioeconomic factors [13].

\subsection{Urban building energy modeling for energy systems planning and urban planning}

Many of these emerging urban-scale models are largely demand-focused, in that the purpose of modeling is to predict annual energy demand of buildings and quantify the efficacy of energy saving retrofit measures. The authors' research focus, however is a different one. We are using energy demand predictions of highly dense mixed-use districts with urban energy supply systems in mind. We propose to use urban building energy models for two main purposes: (1) for the planning and optimization of urban energy systems and (2) for the planning and optimization of urban development.

To optimize supply systems, considering control strategies like peak shaving and load shifting, spatiotemporal patterns of energy demand in the district are needed. The spatial aspect is of significance because thermal systems, such as district heating or cooling networks have spatial constraints. To identify advanced concepts of supply, such as the heat cascade [14] or the cold cascade, information about the spatiotemporal usage patterns of buildings in the district are needed.

To make use of concepts of energy-driven urban design [11], we need to understand how cities change with people, i.e., how scenarios of demographic and socioeconomic changes impact the future energy demand patterns of a district and with it the requirements for district energy supply and distribution systems. This is important given the long planning time horizons of district infrastructure. The official "London Heat Network Manual" for example recommends to aspire to a 50 year life-span for properly designed and installed heating networks [15].

\subsection{Key challenges in simulating on the urban-scale versus the building-scale}

Simulating spatiotemporal patterns of building energy demand at urban-scale is more complex than at building-scale. On the one hand large amounts of information about built structures are needed and the urban environment of each building has to be considered, while on the other hand also the diversity of occupant behavior at the urban-scale influences the spatiotemporal patterns of energy demand [16]. It is for example well known that the maximal total power demand in a district is different from the sum of the individual buildings' maximal power demands [17]. For a case study in China An et al. [18] demonstrated that oversimplified assumptions about occupant behavior leads to a significant overestimation of the peak cooling loads resulting in the design of oversized, inefficient district cooling systems. 
A key difference between building-scale and urban-scale energy modeling are the various system interactions that should be considered in urban contexts [19]. They include interactions between buildings and their surroundings and interactions between buildings and occupants. One such interaction, that seems to be somewhat overlooked until now in urban building energy modeling, is the interaction of single occupants with multiple buildings in the district. E.g., an occupant that is absent from an office at lunch time is likely to be present in a restaurant nearby. Such considerations are common in land-use and transport modeling and simulation [20].

On top of that, building-scale energy modeling rarely considers the long time spans of urban development in which changes in socioeconomic boundary conditions could change occupant behavior and thus impact buildings' energy demand. In residential electric load curve models for the planning of electric infrastructure for example, scenarios of socioeconomic evolutions and behavioral changes of occupants are commonly considered [21].

Occupant activities and behavior, their diversity and their evolution over time should therefore be looked at in the context of urban building energy modeling.

\subsection{Occupant behavior - one reason for the performance gap}

Occupant behavior is one of the main reasons for systematic discrepancies between the calculated or expected energy demand in buildings and the actual energy consumption - the performance gap [9, 22]. The cause is related to the use of unrealistic input parameters regarding occupant behavior and facilities management in building energy models [22] and the high sensitivity of occupant behavior parameters [23]. In a recent model that generates detailed thermal energy demand profiles at the district level, the behavior of occupants was the most important variable [24]. Especially heating and cooling set point temperatures, which directly relate to occupant comfort preferences and behavior are some of the most influential parameters in simplified building stock models [25] and bottom-up engineering urban building energy models [26].

First research that looks at the interdependencies between occupant behavior and urban design showed that age and family structure of occupants should be considered when designing low carbon residential districts. For a case study based on surveys and building energy simulation in China Ruan et al. [27] found that the energy demand of older occupants is more affected by urban design parameters (Floor Area Ratio, Building Coverage Ratio, and Aspect Ratio) as a result of their higher heating energy demand.

\subsection{Occupant behavior in urban-scale building energy models}

Different aspects of occupant behavior are usually modeled separately. Occupant presence models, which are often called occupancy models, describe the presence, absence and movement of occupants in spaces. Occupant action models describe various types of adaptive and non-adaptive behavior, such as adjusting blinds, opening windows, switching lights, and the use of appliances. Occupant activity models link presence and activities of occupants and can consider the use of appliances, lighting or water related to these activities [28, 29]. Recently, extensive reviews about existing models, the current state-of-the-art research and future challenges for occupant behavior modeling on the building-scale have been published [30, 31, 32, 33, 34].

Urban building energy models typically use databases of archetypical construction properties or define a number of prototypical reference buildings. Archetypes and reference buildings are usually classified according to their occupancy type and contain typical occupant behavior properties. Often, a building occupancy type is primarily distinguished by its occupant presence schedule [35].

The main concerns with occupant behavior on the urban-scale are the diversity among buildings of the same occupancy type, that should be accounted for to obtain realistic energy demand patterns [36, 37] and the impacts of behavioral changes over time onto building energy demand [9]. Preliminary research on urban-scale occupant behavior models concludes that stochastic approaches, rather than deterministic, should be considered when high resolution temporal behavior and realistic peak loads are important [18, 38, 39]. On the other hand, for studies based on monthly or yearly energy consumption, the effect of human behavior might not be significant due to averaging effects [39]. In their review on building stock modeling Brøgger and Wittchen [9] speculate that it might not be necessary to model the energy demand of individual buildings exactly, but general trends of socioeconomic and behavioral changes have to be captured.

Recent publications point out that appropriate occupant behavior models and the impact of occupant behavior on energy use at various temporal and spatial resolutions have to be further studied [35, 18]. This work aims to be a contribution towards research on occupant behavior models for urban building energy simulations. 
The objective of this work is therefore to review, categorize and compare occupant behavior modeling approaches used in bottom-up engineering models for urban building energy modeling.

\section{Categorization}

\subsection{Selection criteria}

This work aims at presenting a comprehensive review of occupant behavior in urban building energy models. 43 publications between 2003 and 2017 are considered. Many use cases of such models require at least hourly resolution energy demand profiles. That is why approaches that use a low time resolution, defined here as a simulation time step larger than 1 hour, are excluded.

We categorize the occupant behavior modeling approaches according to two modeling techniques (deterministic vs. stochastic) and two levels of granularity (space-based vs. person-based). Their combination would in principle result in four categories, see figure 11. However, only three were encountered. They are: (1) deterministic space-based approaches, (2) stochastic space-based approaches, and (3) stochastic person-based approaches. These three categories were further divided into sub-categories according to whether they are able to account for inter-individual diversity among spaces or persons, respectively. The modeling techniques, levels of granularity and strategies for diversity are introduced in the following sections.

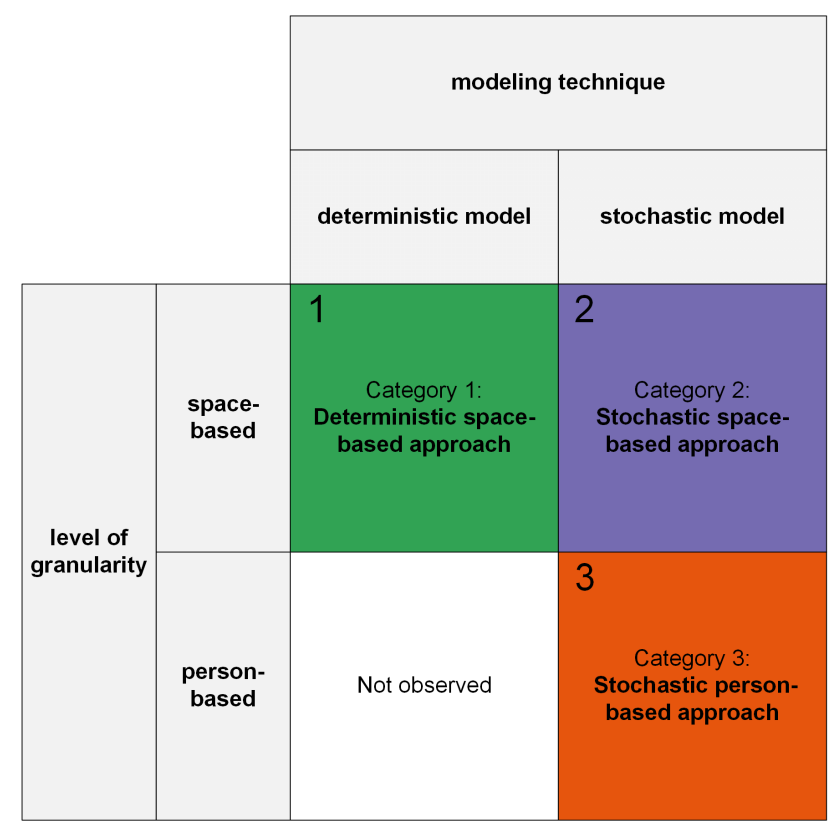

Figure 1: Logic of the categorization of occupant behavior modeling approaches in urban building energy models according to modeling technique and level of granularity.

\subsection{Modeling techniques}

We distinguish between two main occupant behavior modeling techniques usually used for building performance simulations: Deterministic models and stochastic models. In sections 2.2.1 and 2.2.2 the main characteristics of the two are introduced. 


\subsubsection{Deterministic models}

Deterministic models include schedules and deterministic rule sets. To model occupants' presence and non-adaptive actions usually schedules are used. Schedules, also called diversity factors, profiles, or typical load shapes, are represented by numbers between zero and one. They relate the variable consumption of appliances, lighting, etc. to its respective peak consumption/installed power density or the number of occupants present in a certain space to its design capacity/occupant density. Different sets of 24-hour schedules for weekdays, weekends and other sets of important daily variations are usually based on monitored data or a mix of engineering methods and data monitoring [40]. Examples are schedules of occupant presence, lighting use, appliance use, etc. for every hour of a typical day. They are usually published in standard calculation procedures for building energy demand, e.g. [41, 42], or building science literature, e.g., [43, 44, 45, 46]. To model occupants' adaptive actions in buildings deterministic rule sets can be used. Deterministic rule sets assume direct causal links between certain drivers and an action. E.g., occupants open windows as a function of a fixed indoor air temperature threshold or according to a minimum required ventilation rate. They are often implicitly included in building energy models, e.g., [47]. Deterministic models result in fully repeatable and predictable behavior without any variation.

\subsubsection{Stochastic models}

Stochastic occupant behavior models typically sample from statistical distributions to predict the likelihood that certain situations or actions occur. They take into account correlations between observed behavior and environmental stimuli or the occurrence of specific events, e.g., the arrival of an occupant in the space or the clock time. Stochastic occupant presence models are usually based on first-order Markov chain techniques. A variety of residential active occupancy models based on time-inhomogeneous Markov Chain Monte Carlo techniques exist [28, 48, 49, 37, 50]. Their transition probability matrices are commonly derived from local time-use survey (TUS) data, describing human activities in form of a journal. Residential activity chain models are usually also based on TUS data. They stochastically model the daily activities of household members, e.g., [29]. Activities can be linked to power demand of lights or appliances used during a certain activity. With this approach it is possible to generate residential electric load, gas, and water usage profiles [51,52,53, 54, 55, 56] as a function of household demographics. Office occupant presence models based on Markov Chain techniques are usually derived in a similar way from measured occupancy data [57, 58, 59]. Action models for environmental controls, e.g., window openings [60], lights [61] or thermostat adjustments [62] employ various stochastic methods and rely usually on sensor or observation data. By predicting probabilities of actions these models capture more variations in behavior and they can include behavior that cannot be explained by external, objective variables, such as e.g., indoor air temperature or daylight illuminance.

Recent publications for the building-scale researched on the sensitivity of simulation results to modeling techniques [63] and the effects of using stochastic models for occupant presence at different spatial scales within a single-use building [64]. They concluded that reliable estimations of real occupant behavior are more important than the question of modeling technique [63] and that for a large number of buildings deterministic models suffice due to the averaging effects of stochastic models [64]. However, both studies focused on annual energy demand and single building peak loads and not on temporal characteristics of aggregated load patterns.

\subsection{Levels of granularity}

We distinguish between two levels of granularity in occupant behavior modeling approaches: Space-based and person-based approaches. The main characteristics of the two are introduced below.

\subsubsection{Space-based approaches}

Space-based approaches directly model the impact of aggregated occupant behavior in a space of a certain category. A space in an urban building energy model could be an archetypical building, or a thermal zone or a functional zone inside a building, depending on the spatial resolution of the overall model. Examples of space-based approaches include models for occupant presence, space heating and cooling controls and ventilation rates for typical space occupancy types in building energy modeling standards, e.g., [41, 42]. The output of space-based approaches are e.g., the number of occupants present in a space, the status of a heating system in a space or the aggregated electrical power consumption of appliances in a space. Space-based approaches are governed by space-based model parameters, e.g., the nominal occupant density, the heating set point temperature, or the installed appliance power density. 


\subsubsection{Person-based approaches}

Person-based approaches model every individual's presence, activities and actions. The outputs of person-based approaches are e.g., the presence of a specific person in a certain space, the control action of a specific person towards the heating system, or the appliance used by a specific person. Person-based approaches are governed by the individual characteristics and behavioral patterns of each person-category (e.g., full time employed resident, part time employed resident, unemployed resident, etc.). The aggregated presence and actions of all persons in a certain space yield the same model output as a space-based approach. Examples of person-based approaches include the agent-based stochastic occupancy simulator for office buildings by Chen et al. [65, 66].

\subsection{Strategies for diversity}

As introduced in section 1.3 the inter-individual diversity of occupant behavior is of concern at the urban-scale. Following the observations by O'Brien et al. [67] and Haldi [68] on the building-scale, we consider three general strategies to account for inter-individual occupant diversity on the space-level or person-level: (1) the use of measured data for simulation (e.g., real occupant densities for individual buildings), (2) the use of distinct models for distinct person-types (e.g., active and passive occupants) or space-types (e.g., residential space with high appliance power density and low appliance power density), and (3) the use of a general model with metamodels that define the model parameter distributions (e.g., occupant densities for individual buildings sampled from a probability distribution). Novel statistical models that consider inter-occupant diversity on the building-scale include e.g., the models by Haldi et al. [69, 68] for occupant actions on windows, shading and lighting in office and residential environments.

We primarily distinguish between approaches that do not consider diversity and approaches that do consider diversity by any of the possible strategies. We encountered diversity in space-based as well as person-based modeling approaches using deterministic as well as stochastic techniques. We sub-categorize the three occupant behavior modeling approach categories into non-diverse and diverse approaches and describe the chosen method to consider diversity.

\subsubsection{Diversity in space-based approaches}

Variations of all three strategies were encountered in space-based approaches: The use of real data, e.g., building occupant density in [19], the use of discrete space typologies, e.g., the use of discrete sets of appliances in residences [17], and the use of probabilistic distributions of model parameters. One way of obtaining such parameter distributions is by automated calibration of occupant behavior model parameters. There are three techniques for the automated calibration of bottom-up building energy models: meta-modeling, optimization, and Bayesian calibration [36, 70]. Studies that use Bayesian calibration [71, 10] characterize each parameter undergoing calibration as a probability distribution. Each realization of such a model will therefore contain a different set of parameters. This is equivalent to diversity strategy 3. On the other hand, Studies that use optimization calibration [72] result in a unique but constant value of each parameter. This is very similar to using actual data for simulation, i.e., diversity strategy 1. Calibration with meta-modeling, involving the creation of a simplified surrogate model, has not been encountered in the review process.

\subsubsection{Diversity in person-based approaches}

In person-based approaches we only encountered variations of diversity strategy 2. Persons are assigned typical behavioral patterns according to their observed prevalence in surveys using clustering methods e.g., [18, 73]. Approaches considering synthetically sampled persons or persons exhibiting changing or emerging behavioral patterns were not encountered.

\section{Models}

Figure 3 shows the number of publications in each category and sub-category per year. It includes journal, books and conference publications. The first models emerged in 2003/2004 in Japan using stochastic person-based approaches. It seems that urban building energy modeling became popular in 2015, with deterministic space-based occupant behavior models as overwhelming majority of approaches. Also since 2015 more and more approaches consider diversity in behavior. The following sections 3.1, 3.2 and 3.3 describe and discuss each of the three categories. 

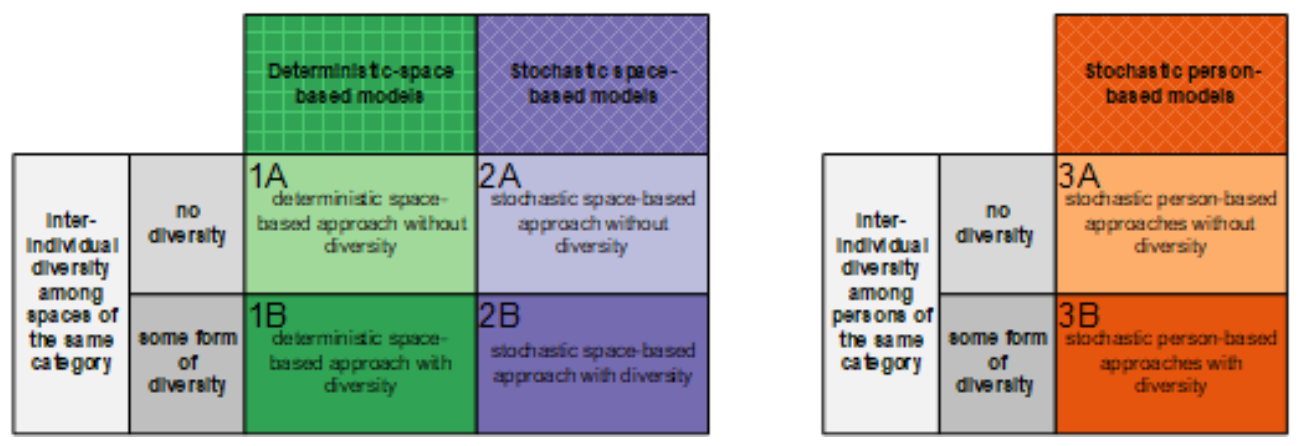

Figure 2: Logic of sub-categorization of urban occupant behavior modeling approaches according to their level of diversity.

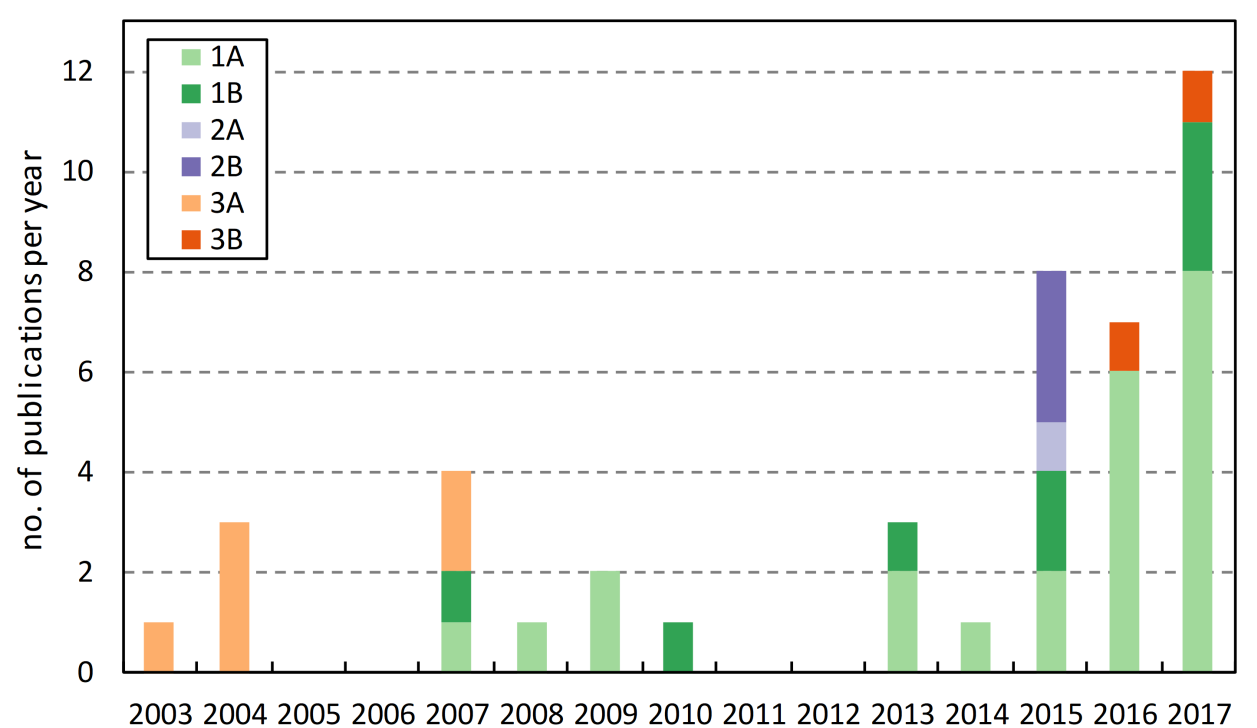

Figure 3: Number of publications on urban building energy modeling per year in each category and sub-category of occupant behavior modeling approach. 


\subsection{Deterministic space-based approaches}

Urban building energy models and tools that use deterministic space-based approaches often focus on the automated generation of building models from 2D GIS or 3D CAD data in conjunction with databases of archetypical construction and typical occupant behavior. They use detailed multi-zone (EnergyPlus, eQuest, DOE-2 or IDA-ICE) building energy simulation tools or simplified existing (Modelica AixLib, HASP) or custom thermal resistance-capacitance-models (R-C-models). Their space-based deterministic occupant behavior models often use standard schedules of building energy standard calculation procedures such as ASHRAE 90.1 [1 [74, 41] or SIA 2024 [2] [42]. Alternatively, they use predefined reference building energy models from the U.S. Department of Energy (DOE) 3 [75, 76] ready available as EnergyPlus models. One study uses the occupant behavior model of commercial software another one extracts schedules from measured data.

\subsubsection{Deterministic space-based approaches without diversity}

Urban building energy models with deterministic space-based approaches without diversity are listed in table 1 All models and tools are briefly introduced in this section.

Heiple and Sailor [77] simulate 22 commercial building prototypes and 8 residential building prototypes to obtain hourly, spatial anthropogenic heat emission profiles. Schedules for occupancy, lighting, internal loads and HVAC systems are based on ASHRAE and the National Renewable Energy Laboratory (NREL) benchmark definitions [74, 94]

Kämpf and Robinson [78] present the CitySim tool. According to [79] deterministic rules and schedules describing occupants' presence and behavior are implemented. In a case study, envelope retrofit strategies are optimized.

Caputo et al. [3] simulate the annual final energy consumption for heating, cooling, domestic hot water, cooking, and lights and equipment of 56 reference buildings with EnergyPlus. Two building occupancy types, residential and office, are diversified in terms of internal loads, air changes and occupant presence schedules obtained from context-specific literature. The model is used to assess the potentials of building envelope and system retrofits.

The urban modeling interface (UMI) by Reinhart et al. [80] couples building geometries to EnergyPlus. Cerezo Davila et al. [5] auto-generate multi-zone thermal models of around 100000 buildings with UMI. A set of 52 archetypes for 4 periods of building age and 13 building occupancy types $4^{4}$ is considered. Occupancy-related parameters including internal peak loads for equipment and lighting use, HVAC system settings and usage schedules are defined for each archetype based on ASHRAE standards. Hourly load profiles of electricity and heating fuel usage are produced for the hottest and the coldest day of the year. Three mixed-use neighborhoods are selected for a study on demand response operation strategies of district energy systems, including the controlled manipulation of HVAC set point temperatures.

Orehounig et al. [81] use EnergyPlus to generate hourly space heating demand by simulating one representative building for 6 categories differing in occupancy type and age of building. Schedules of occupant presence and appliance use according to building occupancy type are taken from SIA. The results are used to assess the integration potential of distributed energy systems at neighborhood-scale, the evaluation of the retrofitting potential, and the identification of the optimal mix of renewable energy sources together with energy conversion technologies.

The City Energy Analyst (CEA) is a tool by Fonseca et al. [2, 82]. Geometric properties of buildings are combined with occupancy-related properties from an archetypes database. The combination of 16 building occupancy types 5 6 construction periods and 6 renovation periods result in 172 building archetypes. Each building occupancy type is linked to an SIA standard schedule of occupant presence, minimum ventilation rates, temperature and humidity set points, and hourly electric load values for appliances, lighting, server rooms and cold rooms. Additional values for

\footnotetext{
${ }^{1}$ The American Society of Heating, Refrigerating and Air-Conditioning Engineers compiled various schedules in [74] that were later published in the Guidebook for the building performance calculation method in Standard 90.1 - Energy Standard for Buildings Except Low-Rise Residential Buildings [41].

${ }^{2}$ The Swiss Society of Engineers and Architects published room-level standard occupant presence, lighting and appliance use schedules as well as HVAC settings for various building functions to be used in the standard calculation procedure of ISO 13790 - Energy performance of buildings Calculation of energy use for space heating and cooling [42].

${ }^{3}$ The U.S. Department of Energy Commercial Reference Building Models contain detailed deterministic occupant behavior schedules [75 76].

${ }^{4}$ Residential, Retail, Office, School/Daycare, Medical/Lab/Production, Fire/Police, Convention/Assembly, Supermarket, Hotel, Restaurant, Worship, Garage, Warehouse/Storage

${ }^{5}$ multiple dwelling unit, single dwelling unit, administrative, hotel, self-service restaurant, restaurant, multipurpose hall, ice hockey stadium, sport arena, fitness studio, cold room, data center, store/department store, supermarket, public building, deposit/garage
} 
Table 1: Reviewed urban building energy modeling studies and tools that use space-based deterministic approaches and do not consider inter-individual diversity (sub-category 1A). Publications about the same urban building energy model are combined in one row.

\begin{tabular}{|c|c|c|c|c|c|c|}
\hline category & study / tool & $\begin{array}{l}\text { implemented occupant behav- } \\
\text { ior sub-models }\end{array}$ & origin of sub-models & $\begin{array}{l}\text { no. occupancy } \\
\text { types }\end{array}$ & $\begin{array}{l}\text { building simulation } \\
\text { engine }\end{array}$ & source \\
\hline $1 \mathrm{~A}$ & Heiple and Sailor & $\begin{array}{l}\text { presence, } \\
\text { lighting, appliance and HVAC } \\
\text { use }\end{array}$ & $\begin{array}{l}\text { ASHRAE, } \\
\text { NREL }\end{array}$ & 12 & eQuest, DOE-2 & 77 \\
\hline $1 \mathrm{~A}$ & CitySim & $\begin{array}{l}\text { presence, } \\
\text { behavior rules }^{\mathrm{a}}\end{array}$ & $\mathrm{n} / \mathrm{a}$ & $\mathrm{n} / \mathrm{a}$ & custom R-C-model & \begin{tabular}{|l|l|}
78 & 79 \\
\end{tabular} \\
\hline $1 \mathrm{~A}$ & Caputo et al. & $\begin{array}{l}\text { presence, } \\
\text { internal loads, } \\
\text { ventilation }\end{array}$ & literature & 2 & EnergyPlus & 3 \\
\hline $1 \mathrm{~A}$ & UMI & $\begin{array}{l}\text { presence, } \\
\text { lighting, appliance and HVAC } \\
\text { use }\end{array}$ & ASHRAE & 13 & EnergyPlus & \begin{tabular}{|l|l|}
80 & 5 \\
\end{tabular} \\
\hline $1 \mathrm{~A}$ & Orehounig et al. & appliance and lighting use & SIA & 3 & EnergyPlus & 81 \\
\hline $1 \mathrm{~A}$ & CEA & $\begin{array}{l}\text { presence, } \\
\text { lighting, appliance and HVAC } \\
\text { use, } \\
\text { hot water use }\end{array}$ & SIA & 16 & $\begin{array}{l}\text { R-C-model based } \\
\text { on ISO } 13790\end{array}$ & \begin{tabular}{|l|l|l|l|}
2 & 82 & 83 & 26 \\
47 & & \\
\end{tabular} \\
\hline $1 \mathrm{~A}$ & TEASER & $\begin{array}{l}\text { presence, } \\
\text { lighting and appliance use }\end{array}$ & SIA & 3 & Modelica AixLib & \begin{tabular}{|l|l|l|}
84 & 85 & 86 \\
\end{tabular} \\
\hline $1 \mathrm{~A}$ & CityBES & $\begin{array}{l}\text { occupant presence, } \\
\text { lighting, appliance and HVAC } \\
\text { use }\end{array}$ & DOE & 2 & EnergyPlus & \begin{tabular}{|l|l|l|}
87 & 88 & 89 \\
\end{tabular} \\
\hline $1 \mathrm{~A}$ & Params-NZP & $\begin{array}{l}\text { occupant presence } \\
\text { lighting, appliance and HVAC } \\
\text { use, } \\
\text { hot water use }\end{array}$ & $\begin{array}{l}\text { DOE, } \\
\text { custom }^{\text {b }}\end{array}$ & 34 & EnergyPlus & 90 \\
\hline $1 \mathrm{~A}$ & Nageler et al. & $\begin{array}{l}\text { presence, } \\
\text { internal gains, } \\
\text { HVAC use, } \\
\text { window ventilation }\end{array}$ & SIA, IDA ICE & 4 & IDA ICE & 91 \\
\hline $1 \mathrm{~A}$ & Ahmed et al. & $\begin{array}{l}\text { presence, } \\
\text { lighting, appliance and HVAC } \\
\text { use, } \\
\text { hot water use, } \\
\text { activity level, } \\
\text { clothing level }\end{array}$ & DOE & 6 & EnergyPlus & 92 \\
\hline $1 \mathrm{~A}$ & Wu et al. & $\begin{array}{l}\text { presence, } \\
\text { lighting, appliance and HVAC } \\
\text { use, } \\
\text { hot water use }\end{array}$ & SIA & 1 & EnergyPlus & 93 \\
\hline
\end{tabular}

a "Behavior rules" not further specified.

${ }^{b} 14$ types of army buildings not disclosed 
local domestic hourly water consumption are taken from literature. In [2] the simulation results are used for studies of building retrofits and for the design of district multi-energy systems. In [82] the tool is used to generate spatiotemporal patterns of energy demand for four different scenarios of urban retrofit (changing building form and occupancy types) on the same site. Based on that, district energy supply systems are designed using optimization methods.

The Tool for Energy Analysis and Simulation for Efficient Retrofit (TEASER) by Remmen et al. [84] features a fully automated building model generation from geometry data and archetypical building properties. From the geometry and occupancy type of a building, an interior design is estimated based on thermal zones. Thermal zones are defined as aggregated areas of similar user behavior and thermal conditions. Hourly schedules for occupant presence and internal gains, divided into lighting and technical equipment, are based on SIA standards. TEASER generates reduced order building models in Modelica. For a university campus case study heat loads for the period of 2020-2050 are predicted, considering a yearly retrofit rate. In this way it can be ensured that the designed central heating systems will not be over sized in future scenarios.

The tool of Nageler et al. [91] produces 2.5D IDA ICE building models based on an archetype database according to building type and age. One building is represented by maximum three vertical layered thermal zones. Each zone corresponds to a different use. With the separation of the zones according to different user profiles, different set points for the room air temperature can be considered. The occupant presence model of IDA ICE is used ${ }^{6}$ Occupant presence also controls the ventilation air exchange and window opening behavior. The model is validated against annual measured data for a case of a district heating network connected to a group of 69 buildings consisting of office, school and residential building occupancy types.

Ahmed et al. [92] present a tool based on U.S. DOE EnergyPlus models of reference buildings, including deterministic occupant behavior. In a case study on the building stock of New York City each building is simulated using an individual localized weather file from an urbanized weather forecast model. Spatiotemporal energy demand patterns for heat wave and non heat-wave days are compared.

Wu et al. [93] use EnergyPlus to generate hourly space heating and electricity demand profiles for 11 representative residential buildings. Deterministic occupant presence schedules, heating set points, hot water, lighting, and electricity demands are taken from SIA standards. Up to nine envelope retrofit scenarios are considered for each representative building. The resulting energy demand patterns are used to simultaneously optimize the building energy systems and envelope retrofits.

The City Building Energy Saver (CityBES) by Hong et al. [89] is a tool for retrofit analysis of small and mediumsized office and retail buildings. Chen et al. [88, 87, 96] present case studies using CityBES in downtown San Francisco. EnergyPlus models are created from data on building footprint, age, type, gross floor area, and number of stories, using the Commercial Building Energy Saver Toolkit (CBES) [97]. CBES contains EnergyPlus models of prototypical office and retail buildings, including various envelope and building system retrofit measures. Deterministic occupant behavior models are based on the DOE reference buildings [97].

Params-NZP [90] is a tool based on EnergyPlus for the parametric analysis of communities. It was developed by the US Army Corps of Engineers as a decision-making aid for Army planners and energy managers. The collection of prototypical building models includes 14 Army building types, 16 commercial building types, and 4 residential building types. The tool allows for building-level optimization and optimization of supply and distribution systems. The 16 commercial prototypical buildings are derived from the DOE reference buildings. Details about Army and residential building types and their occupant behavior models are not provided.

\subsubsection{Deterministic space-based approaches with diversity}

Urban building energy models with deterministic space-based approaches with diversity are listed in table 2 . All models and tools are briefly introduced in this section.

The later models by Yamaguchi et al. [99] (see section 3.3 for the earlier models) include up to 21 building-level and room-level occupancy types 7 . Deterministic electricity demand profiles for lighting and appliances is given to

\footnotetext{
${ }^{6}$ This is not further specified, but in IDA ICE the user can select from a set of predefined occupant presence schedules with default smoothing applied 95

${ }^{7}$ office, retail, hotel, hospital in [99]; normal office, offices closing early, offices closing late, office lobby, meeting room, data center, parking, hotel lobby, hotel restaurant, hotel conference, hotel accommodation, hospital lobby, hospital medical treatment, hospital office, hospital bedroom, conference, library, museum, restaurant, shop, vacant in [101
} 
Table 2: Reviewed urban building energy modeling studies and tools that use deterministic space-based approaches and do consider inter-individual diversity (sub-category 1B). Publications about the same urban building energy model are combined in one row.

\begin{tabular}{|c|c|c|c|c|c|c|c|}
\hline category & study / tool & $\begin{array}{l}\text { implemented oc- } \\
\text { cupant behavior } \\
\text { sub-models }\end{array}$ & $\begin{array}{l}\text { origin of } \\
\text { sub-models }\end{array}$ & diversity strategy & $\begin{array}{l}\text { no. of occu- } \\
\text { pancy types }\end{array}$ & $\begin{array}{l}\text { building simulation } \\
\text { engine }\end{array}$ & source \\
\hline 1B & Urban-EPC & $\begin{array}{l}\text { presence, } \\
\text { lighting, appliance } \\
\text { and HVAC use }\end{array}$ & DOE & $\begin{array}{l}\text { occupant density obtained } \\
\text { from census data (strategy 1) }\end{array}$ & 16 & $\begin{array}{l}\text { R-C-model based } \\
\text { on ISO } 13790\end{array}$ & 19 \\
\hline 1B & Suesser and Dogan & $\begin{array}{l}\text { presence, appliance } \\
\text { use }\end{array}$ & $\begin{array}{l}\text { SIA, } \\
\text { measured data }\end{array}$ & $\begin{array}{l}\text { occupant density obtained } \\
\text { by optimization calibration } \\
\text { (strategy 1) }\end{array}$ & 1 & EnergyPlus & 72 \\
\hline 1B & Cerezo et al. & $\begin{array}{l}\text { presence, lighting and } \\
\text { appliance use }\end{array}$ & survey data & $\begin{array}{l}\text { occupant density, HVAC } \\
\text { settings, lighting power ob- } \\
\text { tained by Bayesian calibration } \\
\text { (strategy 3) }\end{array}$ & $1-4$ & EnergyPlus & 71 \\
\hline 1B & DiDeProM & $\begin{array}{l}\text { presence, lighting and } \\
\text { appliance use }\end{array}$ & DOE & $\begin{array}{l}\text { occupant density, lighting } \\
\text { power, appliance power ob- } \\
\text { tained by random sampling of } \\
\text { parametric models (strategy } \\
\text { 3) }\end{array}$ & 1 & EnergyPlus & 24 \\
\hline
\end{tabular}

${ }^{a}$ HASP/ACLD is a Japanese HVAC simulation tool based on the response factor (or weighting factor) method [100].

each floor usage [100]. The approach is considering real data for inter-individual diversity among spaces of the same occupancy type in terms of occupant densities, as Yamaguchi et al. seem to model each building individually based on site surveys (diversity strategy 1). In [99] the model is used to evaluate building level retrofits, district energy system designs and changes to urban form (replacing small prototypical buildings with large ones). In [100] it is studied how the spatial distribution of building forms and occupancy types in commercial districts influences the district energy demand and how different designs of district energy systems and building-level energy conversion systems impact primary energy consumption and anthropogenic sensible heat release. In [101] scenarios of building-level envelope, lighting, appliance and HVAC retrofits are simulated to estimate the reduction potential of operational carbon dioxide emission in a commercial district in Osaka.

URBAN-EPC is a tool by Quan et al. [19] which couples a simplified building energy model to a GIS platform. In their case study of Manhattan the properties of the DOE commercial reference buildings are used. Occupant densities for residential and commercial usages are taken from block-level population and job census data. This corresponds to diversity strategy 1 , using real data to consider inter-individual diversity among spaces of the same occupancy type. The tool's intended use is to inform urban energy policy making.

Suesser and Dogan [72] model three buildings on a university campus using EnergyPlus. Appliance schedules are extracted from metered electricity consumption and occupant presence schedules are based on SIA with adjustments to start and end time according to the metered electricity data. Occupant density and infiltration rate are calibrated to measured heating energy consumption using optimization. The calibration yields significantly different occupant densities for the three buildings. This method of using measured data and optimization can be considered as strategy 1 to account for inter-individual diversity among spaces of the same occupancy type. The model is used to study various retrofitting scenarios and the impacts of climate change onto the buildings' energy demand.

Cerezo et al. [71] address uncertainty related to the inter-individual diversity of occupant behavior by defining certain archetype parameters as probability distributions rather than fixed deterministic values (diversity strategy 3). They simulate 140 residential buildings with generic multi-zone EnergyPlus models based on an archetypes database. Some occupant behavior model parameters are probabilistically defined according to probability distributions 
estimated by Bayesian calibration to measured annual building energy consumption data. They are the cooling set point, the installed lighting, and the buildings' occupant density. Plug loads and the maximum hourly domestic hot water consumption are modeled as linear functions of occupant density. Schedules of occupants' presence and use of appliances are taken from context-specific literature and are not subject to the probabilistic modifications of archetypes. The simulation is used for potential analysis of envelope retrofits in terms of yearly energy demand.

Sokol et al. [10] apply the methodology of Cerezo et al. [71] to a larger sample of buildings. 8 archetypes (4 age bands determining envelope properties and 2 heating system configurations) are defined to study a low-rise residential district. No details about the origin of the deterministic occupant behavior models are provided. 6 selected uncertain parameters are defined as probability distributions: infiltration, heating set point temperature, cooling set point temperature, occupant density, plug load and lighting power density, and the domestic hot water flow rate. A Bayesian calibration procedure against annual and monthly metered data is performed on a training set of buildings. This leads to posterior distributions for uncertain parameters on the district-scale, which are then used to simulate a different set of similar buildings. The authors conclude that probabilistic archetypes rather than fully-deterministic definitions result in a more realistic spread of energy demands. Probabilistic archetypes allow the model to account for inter-individual diversity of occupant behavior within buildings of the same occupancy type. By performing multiple Monte Carlo simulations of such a model, results are presented as probability distributions rather than single values. This allows for example to predict the energy savings from a retrofit measure with a confidence interval around the expected value. However, the authors strongly advise against using such a model to generate hourly load data. Hourly load data is strongly correlated with occupant behavior, and all buildings are using the same archetypical schedules. They state that the time resolution of the calibration data set should be at least as high as the time resolution of any analysis based on the urban model.

Another approach to introduce inter-individual diversity among spaces of the same occupancy type is to vary occupant-behavior-related parameters within certain bounds and randomly select simulated energy demand profiles (diversity strategy 3). Kazas et al. [24] present a District Demand Profile Model (DiDeProM). It a combines a fully deterministic building simulation with a stochastic district demand profile generation method. A detailed EnergyPlus model of a real building is simulated for 4 scenarios of varying building orientation and shading and 75 scenarios of combinations of infiltration rate, occupant density, installed lighting and appliances power densities (total 300 scenarios). The deterministic schedules of occupant presence and appliance and lighting use in the building model are based on the DOE reference buildings [102]. In the second step, these normalized demand profiles are assigned randomly to buildings of similar orientation. The authors state that with this random selection uncertainties regarding occupant behavior can be considered.

\subsection{Stochastic space-based approaches}

Urban building energy models that use stochastic space-based approaches are listed in table 3 . They couple building energy models to stochastic space-based occupant behavior models from literature, such as the Richardson models [28, 56, 103].

Table 3: Reviewed urban building energy modeling studies and tools that use stochastic space-based approaches without diversity (sub-category 2A) and stochastic space-based approaches with diversity (sub-category 2B). Publications about the same urban building energy model are combined in one row.

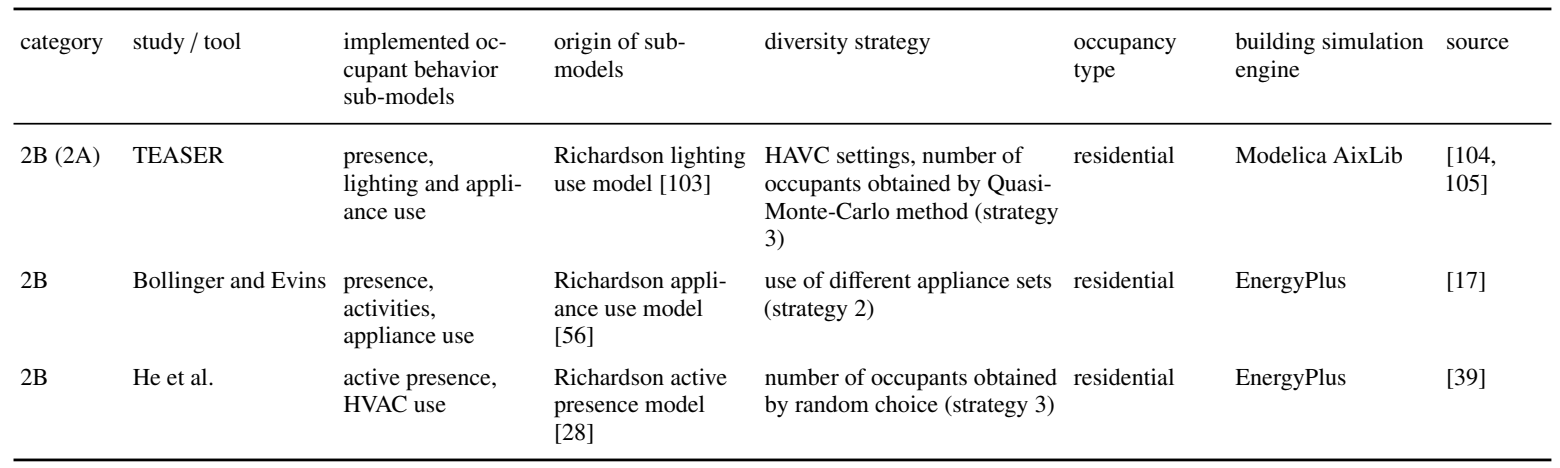


Richardson et al. [28] define the term "active occupant" as a person who is at home and not asleep and pioneered in the use of time-use survey (TUS) data - using a journal to describe what people do and when. Their two-state active occupancy model is based on the first order non-homogeneous Markov Chain Monte Carlo technique that generates synthetic data with the same overall statistics as the original survey data. From UK TUS data separate transition probability matrices were constructed for weekdays and weekends and for different numbers of household residents (one to six residents). This is assumed to better represent simultaneous state changes in households, e.g. the whole family leaving the house at the same time. Building up on this model Richardson et al. [56] present a domestic electricity demand model for individual dwellings based on the activities of the occupants and their associated use of electrical appliances. A similar model for residential lighting use was also developed by Richardson et al. [103]. These models will be called "Richardson active presence model", "Richardson appliance use model" and "Richardson lighting use model" for the rest of this work.

\subsubsection{Stochastic space-based approaches without diversity}

Schiefelbein et al. [104] use the TEASER tool to generate building models of an existing residential district with 248 old buildings. The aim of their case study is to estimate the state of retrofit for district. Building models are generated for different retrofit years. Annual stochastic profiles of occupant presence, appliances and lighting use are generated with a modified version of the Richardson active presence model [28].

\subsubsection{Stochastic space-based approaches with diversity}

In another case study by Schiefelbein et al. [105] TEASER is used to generate and calibrate a model of a reference residential district. Autogenerated building models and stochastic occupant presence and residential electrical load profiles based on the Richardson lighting use model [103] are used to simulate the spatiotemporal thermal and electric energy demand patterns of 55 buildings. The reference district model is calibrated via Quasi-Monte-Carlo uncertainty analysis to measured thermal energy demand of the district. One of the calibration parameters is the number of occupants per thermal zone. This corresponds to strategy 3 (probabilistic parameters) for inter-individual diversity. The electrical load of buildings is then used in an electricity grid model of the district to simulate the operating conditions.

Bollinger and Evins [17] use a stochastic demand module, based on the Richardson appliance use model [56] to generate different occupant presence and electricity demand data for 50 identical residential buildings with different, distinct appliance sets. This corresponds to strategy 2 (distinct models) for inter-individual diversity of spaces. This data is then used as an input in EnergyPlus simulations to produce heat and electricity demand patterns at one-minute time resolution. The results are used to design a district multi-energy system.

He et al. [39] use the Richardson active presence model [28] in EnergyPlus simulations of a residential neighborhood with 125 new buildings. 125 stochastic occupancy profiles are generated to derive the stochastic heating patterns of different rooms according to actively-occupied hours, i.e., the heating system is turned on when at least one occupant is present and active. Each of these heating patterns is then randomly assigned to one of the buildings. This corresponds to strategy 3 (probabilistic parameters) for inter-individual diversity.

\subsection{Stochastic person-based approaches}

Urban building energy models that use stochastic person-based occupant behavior approaches are listed in table 4 They often combine custom-developed behavior models with models from building-scale literature. Their models are typically very data intensive. They build upon measured data or large-scale questionnaire surveys, like national time use surveys. They are therefore limited to building occupancy types for which such data is available, i.e., residential and office occupancy. The individual models are introduced in this section.

\subsubsection{Stochastic person-based approaches without diversity}

For their district energy simulation model, Yamaguchi et al. [98, 106] develop a detailed bottom-up energy demand model including stochastic occupant behavior. They simulate the working states of commercial building occupants. First, working hours are decided based on distribution functions. Each occupant gets the time when he starts and ends work and the times when he leaves to and returns from the lunch break assigned. During the working hours the working state is determined by a homogeneous Markov chain. Properties for four types of jobs (manager, clerk, sales, and engineer) and four working states (using PC, not using PC, being out, and using two PCs) are assumed to generate the 
Table 4: Reviewed urban building energy modeling studies and tools that use stochastic person-based approaches without diversity (sub-category 3A) and stochastic person-based approaches with diversity (sub-category 3B). Publications about the same urban building energy model are combined in one row.

\begin{tabular}{|c|c|c|c|c|c|c|c|c|}
\hline category & study / tool & $\begin{array}{l}\text { implemented oc- } \\
\text { cupant behavior } \\
\text { sub-models }\end{array}$ & $\begin{array}{l}\text { origin of sub- } \\
\text { models }\end{array}$ & diversity strategy & $\begin{array}{l}\text { no. of occu- } \\
\text { pant types }\end{array}$ & $\begin{array}{l}\text { building } \\
\text { occupancy } \\
\text { type }\end{array}$ & $\begin{array}{l}\text { building } \\
\text { simulation } \\
\text { engine }\end{array}$ & source \\
\hline \multirow[t]{2}{*}{$3 \mathrm{~A}$} & Yamaguchi & \multirow{3}{*}{$\begin{array}{l}\text { presence, } \\
\text { activities, } \\
\text { appliance use } \\
\text { presence, activities, } \\
\text { lighting, appli- } \\
\text { ance and HVAC } \\
\text { operation, } \\
\text { hot water use }\end{array}$} & \multirow[t]{2}{*}{ custom } & \multirow[t]{2}{*}{-} & \multirow[t]{2}{*}{4} & \multirow[t]{2}{*}{ office } & \multirow[t]{2}{*}{ HASP $^{\mathrm{a}}$} & \multirow{2}{*}{\begin{tabular}{l|l|}
98 & 106 \\
107 & \\
\end{tabular}} \\
\hline & & & & & & & & \\
\hline $3 \mathrm{~A}$ & Shimoda et al. & & $\begin{array}{l}\text { custom, } \\
\text { (SHASE) }\end{array}$ & - & 8 & residential & $\begin{array}{l}\text { custom R-C- } \\
\text { model } \\
\text { (HASP) }\end{array}$ & \begin{tabular}{l|l|}
108 & 109 \\
110 & \\
\end{tabular} \\
\hline $3 \mathrm{~A}$ & SUNtool & $\begin{array}{l}\text { presence, } \\
\text { appliance use, } \\
\text { window opening }\end{array}$ & literature, custom & - & $\mathrm{n} / \mathrm{a}$ & office $^{\mathrm{c}}$ & $\begin{array}{l}\text { custom R-C- } \\
\text { model }\end{array}$ & 111 \\
\hline 3B & StROBe & $\begin{array}{l}\text { presence, } \\
\text { activities, } \\
\text { lighting and appli- } \\
\text { ance use, } \\
\text { hot water use }\end{array}$ & $\begin{array}{l}\text { custom, } \\
\text { literature }^{\mathrm{d}}\end{array}$ & $\begin{array}{l}\text { typical presence patterns, } \\
\text { space heating settings from } \\
\text { clustering TUS and large- } \\
\text { scale questionnaire survey } \\
\text { (strategy 2) }\end{array}$ & 5 & residential & $\begin{array}{l}\text { Modelica } \\
\text { IDEAS }\end{array}$ & 73 \\
\hline 3B & SOB & $\begin{array}{l}\text { presence, } \\
\text { lighting, appliance, } \\
\text { HVAC and window } \\
\text { operation }\end{array}$ & literature $^{\mathrm{e}}$ & $\begin{array}{l}\text { typical cooling set points, } \\
\text { lighting control, window } \\
\text { operation, HVAC control } \\
\text { from clustering large-scale } \\
\text { questionnaire survey (strategy } \\
\text { 2) }\end{array}$ & 3 & residential & $\operatorname{DeST}^{\mathrm{f}}$ & 18 \\
\hline
\end{tabular}

${ }^{a}$ HASP/ACLD is a Japanese HVAC simulation tool based on the response factor (or weighting factor) method [100].

${ }^{\mathrm{b}}$ The model of Page et al. [58] for occupant presence considering intermediate long absences.

$c$ assumed to be office as the model of Page et al. [58] was developed for office occupant presence.

${ }^{\mathrm{d}}$ The model of Richardson et al. [56 for activity-chain, appliance use and hot water use, the model of Widén et al. [49] for lighting use.

${ }^{\mathrm{e}}$ The model of Wang et al. [59] for occupant presence and movement for zone to zone. The model of Wang et al. 112. 113] was adapted for the operation of HVAC systems, lights and windows.

$\mathrm{f}$ The Designer's Simulation Toolkit (DeST) is a building energy modeling program based on a state-space multi-zone heat balance calculation method developed in China [114. 
transition matrices for the Markov chain. The working states of each occupant are translated into a power consumption and heat release from appliances. This approach is considered to be non-diverse, as no inter-individual diversity in behavior among the same occupant type is modeled. The model is used to evaluate options for district energy systems design for two neighboring office buildings of varying size and energy efficiency measures. The same model is used in [106, 107] for envelope and building systems retrofit studies of 55 large office buildings in a commercial district in Osaka. However, it is unclear whether the original stochastic occupant behavior model is still used, as "common operational conditions" were assumed for all buildings in [107].

In [108, 109] Shimoda et al. create 460 representative residential buildings from 20 categories of buildings and 23 household types 8 Stochastic schedules of living activities are considered for each family member category 9 . The energy use for electric appliances, lighting and cooking are simulated from occupants' living activities at each time step. Detailed models of appliance dissemination ${ }^{10}$ in households and appliance electricity consumption are developed. Later in [110] Shimoda et al. update their model's simulation of the occupant activity-chains. 380 representative buildings are created from 19 household demographics categories and 20 residential building types. For each of the 8 occupant categories ${ }^{11}$ the activity-chain is simulated in time steps of five minutes for 500 days of weekdays and holidays. Simultaneous activities such as watching television while having a meal are considered. For each household category, the activity-chain of each household member for a day is selected at random from the above mentioned 500-day schedules on a daily basis. Each living activity calculated by this simulation is linked with the energy use of appliances and hot water use. The probability of appliance use is also considered for each time period. The location of each living activity is also identified to determine the energy use for heating, cooling, and lighting of specific rooms. A fixed AC cooling set point temperature for all occupants is assumed. This approach is considered to be non-diverse, as no inter-individual diversity in behavior among the same occupant type is modeled. The model is used to study building envelope efficiency improvements, appliance efficiency improvements, and the influence of the urban heat island onto building energy demand. In addition, the authors state that this model has the capability to examine the effects of life style changes on energy consumption, as appliance use is directly linked to occupants' activities. They also state that by considering scenarios of changes in population demographics the model is able to predict the change of energy consumption in the future.

SUNtool by Robinson et al. [111] includes and combines various stochastic models for occupant presence, window opening, lights and shading devices, electrical and water appliances, and waste produced for single buildings or zones. The occupant presence model of Page et al. [58] is implemented. The model of Page et al. [58] is a two-state (absent/present) single occupant, single zone simulation for office spaces based on a time-inhomogeneous Markovchain interrupted by occasional periods of long absence. The transition probabilities are estimated based on aggregate measured occupancy. An assumed parameter of mobility describes the probability of state changes. An additional algorithm for the random start of a period of long absence is executed at each time step. Aggregated hourly occupant presence values produce loads that are considered in the building thermal model. For window opening, a behavioral model relating indoor environmental stimuli with interaction probability is developed. Indoor temperature and pollutant concentration are used to predict interaction probability. People already present in a zone and new arrivals have distinct acceptability of indoor pollutant concentration. People also have a random, normally distributed higher or lower critical temperature limit of comfort. Interactions take place when critical limits of the stimuli are reached, except when occupants are about to leave for a long absence. The consumption of electrical and water appliances is simulated by using a set of stochastic rules depending on the presence of occupants, switch-on probability profiles, exponential distributions of use duration, and, for appliances with varying demand, a Gaussian distribution of power demand. No interactions with HVAC systems are included. This approach is considered to be non-diverse, as no inter-individual diversity in behavior among the same occupant type is modeled. In one case study the building energy consumption as a function of facade glazing ratio and urban street canyon proportions is studied. In a another case the relationship

\footnotetext{
${ }^{8}$ According to number of household members, family type of household and employment status of husband and wife, e.g., 2 household members / aged mother and child / neither husband nor wife is employed, or 6 household members / couple, children and parents / Both husband and wife are employed, etc.

${ }^{9}$ The simulation software 'SCHEDULE' developed by SHASE (The Society of Heating, Air-Conditioning and Sanitary Engineers of Japan) generates schedules of heating and cooling, lighting and other energy use in dwellings from Japanese TUS data.

${ }^{10}$ Active power consumption and stand-by power consumption of 23 appliances are considered.

${ }^{11}$ The types employed male, employed female, housewife, elementary school student, junior high school student, high school student, aged male, and aged female, correspond to the Japanese TUS occupant categories.
} 
between building form, urban form and energy consumption is studied and options for on-site generation of solar energy technologies are explored. SUNtool was further developed into CitySim without keeping the stochastic occupant behavior models.

\subsubsection{Stochastic person-based approaches with diversity}

Baetens and Saelens [73] developed a stochastic residential occupant behavior (StROBe) model for district energy simulations. It simulates plug loads, internal heat gains, thermostat settings and hot water use based on occupant presence and activities. First a household composition is sampled according to the distributions found in Belgian TUS data. 4 types of occupants are distinguished ${ }^{12}$. For each household member one of 7 typical occupant presence pattern ${ }^{13}$ is selected. A three-state stochastic active-occupancy model (awake at home, asleep at home, and absent) is based on a heterogeneous discrete-time Markov chain. The transitions are determined by event density and a survival time density parameters for each of the typical presence patterns. Residential activities, appliance use and hot water use is modeled with an adaptation of the Richardson appliance use model [56]. Lighting loads are modeled with the stochastic domestic lighting demand model of Widén et al. [49]. For space heating behavior patterns an approach using clustered questionnaire data from 15000 Dutch dwellings is developed ${ }^{14}$. The most-active household member at a certain time step determines the heating set point of the living area. In this way StROBe implements strategy 2 (distinct models) for inter-individual diversity in presence and space heating behavior of persons of the same type. A two zone thermal model representative of the Belgian building stock is used. The model is able to produce district energy demand patterns with simultaneity and autocorrelation measures close to the respective design standards. The model is then used to quantify the uncertainty introduced by stochastic occupant behavior on electrical district infrastructure design. Various scenarios of 5 - 30 identical residential buildings and different energy system configurations consisting of PV systems and heat pumps are simulated.

An et al. [18] present a stochastic occupant behavior method (the SOB method) to consider the behavior of multiple occupants for residential district load prediction in China. The SOB method considers variability in occupant presence, cooling set point temperatures and the operation of HVAC systems, lighting and windows. For occupant presence and movement from zone to zone they adopt the approach of Wang et al. [59] originally developed for multi-zone office buildings. It combines time-related events (e.g., reaching home) and stochastic movements from zone to zone in a homogeneous Markov chain. The parameters of the model are the expected proportion of time the occupants spend in every zone in the apartment and the earliest, expected and latest time of each arrival and departure from the apartment [59]. Six typical set of parameters based on household size and type of occupant ${ }^{15}$ are extracted from a large-scale questionnaire survey. Typical cooling set point distributions are derived from the same survey. The approach of Wang et al. [112, 113] is adapted for the operation of HVAC systems, lights and windows. Their conditional probability model considers environment-triggered (e.g., action in response to indoor temperature) and event-triggered (e.g., action when arriving at home) control actions. Environment-triggered action probabilities are defined by three-parameter Weibull cumulative functions - increasing the probability of actions with with increasing exceedance of the threshold value. Probabilities of event-triggered actions are set to a constant value. The case study model parameters are based on reference studies that are not further specified and the authors' assumptions. The frequency of four to five typical behavior modes for each occupant action model (e.g., "AC off when leaving living room", "AC off when sleeping", etc.) are extracted from the questionnaire survey. For appliance loads deterministic schedules are created for each combination of household and apartment type based on experiments. For the case study in a residential district seven prototype apartment energy models are created, a questionnaire is used to survey the frequencies of each typical household composition and occupant behavior type. Stochastic sampling is used to assign household compositions and occupant behaviors to each apartment in the district. In this way SOB implements strategy 2 (distinct models) for inter-individual diversity in presence and HVAC use behavior among persons of the same type. The energy demand of

\footnotetext{
${ }^{12}$ Full time employed, part time employed, unemployed, retired, and minor.

${ }^{13}$ The patterns were clustered from the Belgian TUS data by Aerts 115. They are: Mostly at home, very short daytime absence, short daytime absence, daytime absence, afternoon absence, night-time absence, mostly absent.

${ }^{14} 6$ out of 7 typical household heating behavior patterns including set point and set back temperatures and the extent of heated spaces as described by Leidelmeijer and Van Grieken [116] are considered. E.g., Pattern 3: $18.5^{\circ} \mathrm{C}$ if home and awake, $18.5^{\circ} \mathrm{C}$ if home and asleep, $15.0^{\circ} \mathrm{C}$ if absent, day-zone-space and bathroom are heated.

${ }^{15}$ One office worker; Two office workers; Two retirees; Two office workers and one student; Two office workers, one student, and one retiree; Two office workers, one student, and two retirees
} 
each apartment is simulated using the multi-zone dynamic building simulation tool DeST [114]. The district cooling load pattern is simulated and compared to measured data using three occupant behavior modeling approaches: The SOB method, deterministic schedules from literature and a Chinese HVAC design standard method (assuming constant internal heat gains and constant AC operation). Five relevant performance metrics for district energy systems design and policy making are compared: The total cooling load, the peak load (relevant for infrastructure sizing), the load duration curve (relevant for conversion systems' sizing), the load profile (relevant for operation strategies) and the total load distribution among households (relevant for policy making). The results show that deterministic schedules and stochastic occupant behavior models can be used to predict total cooling consumption. For peak load estimation only the stochastic method is sufficient. The use of deterministic schedules results in a large error of $150 \%$. None of the methods is able to accurately reproduce the district load duration curve and the load profile. However, the SOB method outperforms the two deterministic methods. Regarding the load distribution, the SOB method predicts similar distributions as the measurement data. Although only occupant behaviors of the majority of the population in the district (no extreme behaviors) are considered.

\section{Discussion}

\subsection{Summary}

Table 5 compares all reviewed urban building energy models in terms of their capabilities to model different building occupancy types. Table 6 lists the actual and intended modeling purposes of the reviewed publications. Intended modeling purposes are often mentioned in the outlook sections of publications.

\subsubsection{Deterministic space-based approaches}

Deterministic space-based approaches seem to be the primary choice of developers of urban building energy modeling toolsets (CitySim, UMI, CEA, TEASER, CityBES). These tools are usually capable of modeling various building occupancy types. UMI and CEA offer the most comprehensive set of building occupancy types by implementing standard occupant presence and behavior schedules, see table 5. Other reviewed urban building energy models of this category are based on classical building-scale simulation tools (DOE-2, eQuest and EnergyPlus), which rely on the input of schedules of occupant presence, lighting use, appliance use and so on. Such models and tools are usually used for larger city-scale or district-scale case studies. Their purposes include building retrofit studies and district energy system design and operation studies, see table 6 . In the case of retrofit potential analysis the choice of deterministic occupant behavior seems appropriate, as the optimized retrofit strategies are obtained as an indicative value for classes of buildings. The design of district energy systems, however, relies on accurate estimation of peak demands. Models with deterministic occupant behavior might not be the optimal choice for this application. Studies using stochastic occupant behavior models showed that peak loads on the district-scale are affected by the stochasticity of demand patterns in buildings. However, deterministic models based on standard schedules of occupant presence seem to be the only option if mixed-use case studies with buildings of various occupancy types ought to be modeled. They are available in norms and standards or in the respective building-scale simulation literature and they can easily be input to the commonly-used building energy simulation tools.

Diversity in deterministic space-based approaches is considered via real data (diversity strategy 1) either by setting parameter values to actual observations from other data sources, e.g., office occupant density according to job census data [19] or by calibrating parameter values to measured energy consumption using optimization algorithms, e.g., [72]. Two options of diversity strategy 3 (probabilistic model parameters) for deterministic space-based approaches were discovered: (1) Equip archetypes with probabilistic occupant-behvaior-related parameters, e.g., [71, 10, 105], or (2) simulate sensitivity-like variations of occupant-behavior-related parameters to generate a database of heating patterns or normalized load curves and randomly assign such patterns to buildings in the case study e.g., [24]. By performing multiple Monte Carlo simulations of such a model, results are obtained as probability distributions rather than single values. This allows for example to predict the energy savings from a retrofit measure with a confidence interval around the expected value. Residential buildings are the only occupancy type considered in approaches using this diversity strategy, see table 5 . 
Table 5: Building occupancy type categories considered in the reviewed occupant behavior modeling approaches. Publications are ordered according to their occupant behavior modeling approach category and the number of included building occupancy types.

\begin{tabular}{|c|c|c|c|c|c|c|c|c|c|c|c|c|}
\hline category & study/tool & 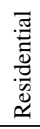 & $\stackrel{\mathscr{E}}{\mathscr{E}}$ & 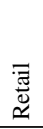 & 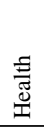 & 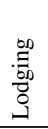 & $\begin{array}{l}\stackrel{0}{0} \\
\stackrel{0}{0} \\
\text { 苛 }\end{array}$ & 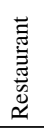 & 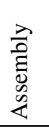 & 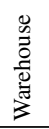 & 离 & source \\
\hline $1 \mathrm{~A}$ & UMI & & & & & & & & & & & \begin{tabular}{|l|l|}
80 & 5 \\
\end{tabular} \\
\hline $1 \mathrm{~A}$ & CEA & & & & & & & & & & & \begin{tabular}{|l|l|l|}
2 & 82 & 83 \\
\end{tabular} \\
\hline $1 \mathrm{~A}$ & Heiple and Sailor & & & & & & & & & & & 77 \\
\hline $1 \mathrm{~A}$ & Params-NZP & & & & & & & & & & & 90 \\
\hline $1 \mathrm{~A}$ & Ahmed et al. & & & & & & & & & & & 92 \\
\hline $1 \mathrm{~A}$ & Nageler et al. & & & & & & & & & & & 91 \\
\hline $1 \mathrm{~A}$ & Orehounig et al. & & & & & & & & & & & 81 \\
\hline $1 \mathrm{~A}$ & CityBES & & & & & & & & & & & \begin{tabular}{|l|l|l|}
87 & 88 & 89 \\
\end{tabular} \\
\hline $1 \mathrm{~A}$ & TEASER & & & & & & & & & & & \begin{tabular}{|l|l|l|}
84 & 85 & 86 \\
\end{tabular} \\
\hline $1 \mathrm{~A}$ & Caputo et al. & & & & & & & & & & & 3 \\
\hline $1 \mathrm{~A}$ & Wu et al. & & & & & & & & & & & 93 \\
\hline $1 \mathrm{~A}$ & CitySim & & & & & & & & & & & \begin{tabular}{|l|l|}
78 & 79 \\
\end{tabular} \\
\hline $1 \mathrm{~B}$ & Urban-EPC & & & & & & & & & & & 19 \\
\hline $1 \mathrm{~B}$ & Yamaguchi et al. & & & & & & & & & & & \begin{tabular}{|l|l|l|}
99 & 100 & 101 \\
\end{tabular} \\
\hline 1B & Suesser and Dogan & & & & & & & & & & & 72 \\
\hline 1B & DiDeProM & & & & & & & & & & & 24 \\
\hline 1B & Cerezo et al. & & & & & & & & & & & 71 \\
\hline 1B & Sokol et al. & & & & & & & & & & & 10 \\
\hline $2 \mathrm{~B}(2 \mathrm{~A})$ & TEASER & & & & & & & & & & & $104 \quad 105$ \\
\hline $2 \mathrm{~B}$ & Bollinger and Evins & & & & & & & & & & & 17 \\
\hline $2 \mathrm{~B}$ & He et al. & & & & & & & & & & & 39 \\
\hline $3 \mathrm{~A}$ & Yamaguchi et al. & & & & & & & & & & & \begin{tabular}{|l|l|l|}
98 & 106 & 107 \\
\end{tabular} \\
\hline $3 \mathrm{~A}$ & SUNTool & & & & & & & & & & & 111 \\
\hline $3 \mathrm{~A}$ & Shimoda et al. & & & & & & & & & & & \begin{tabular}{|l|l|l|}
108 & 109 & 110 \\
\end{tabular} \\
\hline $3 \mathrm{~B}$ & StROBe & & & & & & & & & & & 73 \\
\hline $3 \mathrm{~B}$ & An et al. & & & & & & & & & & & 18 \\
\hline
\end{tabular}


Table 6: Demonstrated (dark gray) and intended (light gray) purposes of the reviewed urban building energy models. The models are ordered according to their occupant behavior modeling approach category.

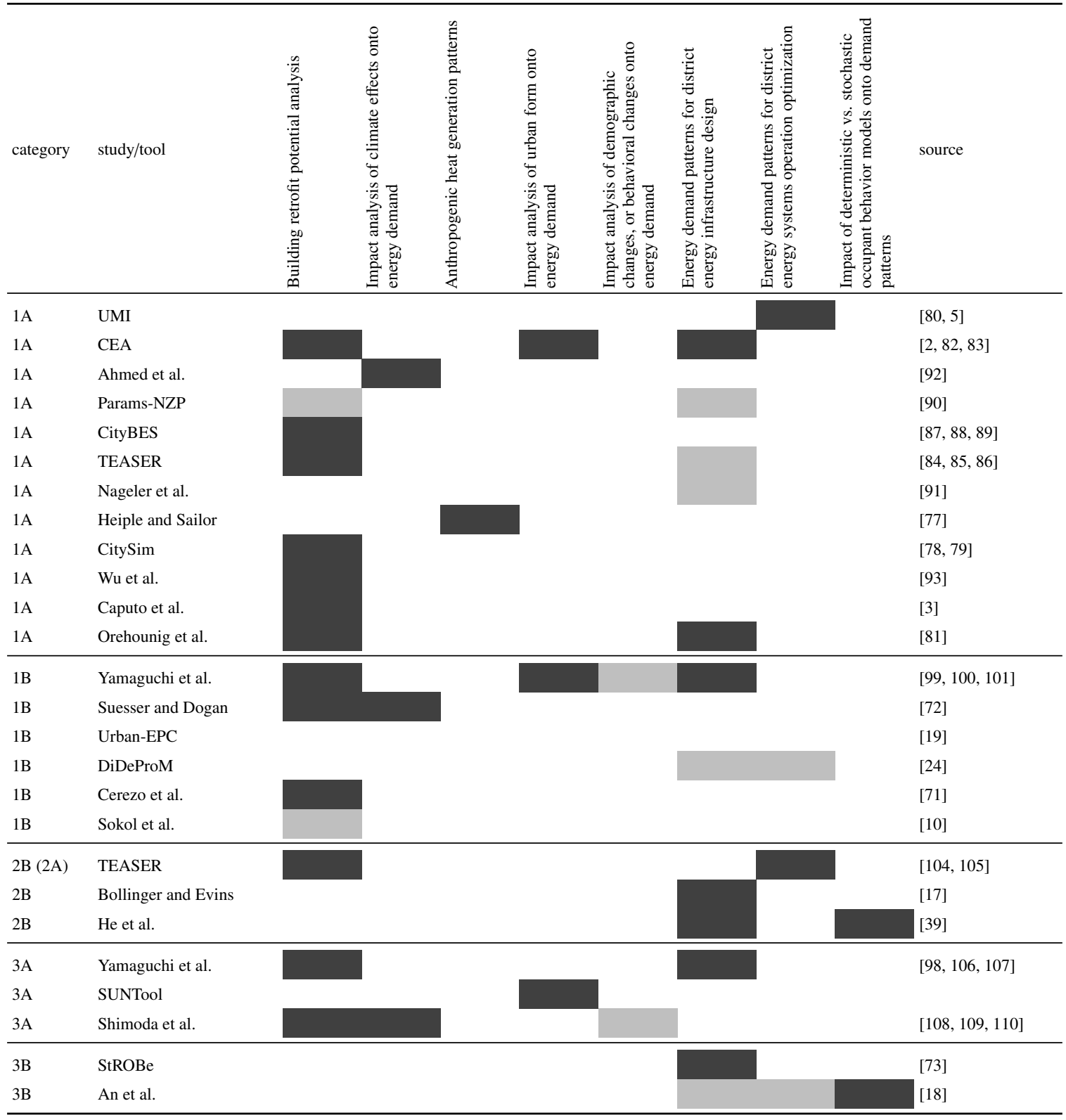




\subsubsection{Stochastic space-based approaches}

Only a small number of stochastic space-based approaches were encountered in the review process. The reviewed publications of this category couple existing building energy models (in EnergyPlus or Modelica) to existing stochastic space-based occupant behavior models of Richardson et al. [28, 103, 56]. The models of of Richardson et al. were developed for the residential context and build upon data of UK TUS, which is maybe not appropriate in other contexts. Unless new stochastic occupant behavior models for other building occupancy types and contexts are developed, this category remains limited by the availability of suitable building-scale models. The publications that use this approach primarily research the impacts of stochastic vs. deterministic occupant behavior on resulting spatiotemporal patterns of energy demand [39] and their respective implications for district energy systems design [17]. In [17] it is demonstrated that stochastic occupant behavior affects the sizing of district energy systems. In [39] stochastic occupant presence in residential buildings results in aggregated heating demand patterns on weekends that are different from commonly-assumed standard heating hours. However, the effects on the design of district energy systems were not quantified in any of the studies. The approaches in this category make use of diversity strategy 2 (distinct models) and diversity strategy 3 (probabilistic model parameters).

\subsubsection{Stochastic person-based approaches}

Stochastic person-based approaches are implemented in some of the earliest urban building energy models. They originated from Japan and typically require access to large TUS and behavior questionnaire survey data in the relevant context. The approach by Shimoda et al., using stochastic residential activity chains according to household demographics is used to study impacts of building retrofits and the urban heat island. It does not seem that occupant behavior directly influences any of the scenarios under investigation and that for these modeling purposes a simpler modeling approach could be appropriate. However, the model of Shimoda et al. [108] is the only one among the reviewed literature that has the theoretical capability to predict future energy consumption considering changes in life style and population demographics. Baetens and Saelens [73] and An et al. [18] present the most comprehensive and most diverse stochastic person-based occupant behavior modeling approach for the residential context so far. They are considering diversity of distinct behavioral patterns amongst persons of the same category according to clustered observations. An et al. were also the only ones who examine the effects of using deterministic space-based approaches vs. a stochastic person-based approach onto district energy systems design. They demonstrate the superiority of stochastic person-based approaches for this purpose of urban building energy models.

Overall it can be observed that for the urban-scale various deterministic and stochastic models have been adopted from building-scale research with little or no modifications. Among the reviewed publications there are no stochastic approaches that cover more than a single building occupancy type. On the district-scale only residential and office occupancy types are modeled using stochastic approaches. Two studies were reviewed that directly compare the effects of using stochastic occupant behavior approaches to deterministic ones on the urban-scale [39, 18], see table 6. Both of them are considering residential buildings only. Both of them confirm the superiority of stochastic occupant behavior models over deterministic ones. Urban building energy models with deterministic space-based occupant behavior approaches have been used for district energy sizing and operation strategies, but first results of comparative studies advise against using such models, because relevant performance metrics were predicted with large errors when using deterministic approaches [18]. However, in many publications the occupant behavior modeling approaches are still only side notes. An approach considering the potential evolution of occupant behavior over time was not encountered in the review process.

\subsection{Activity-based multi-agent approaches as an alternative for stochastic urban-scale occupant behavior}

In general, stochastic person-based occupant behavior approaches offer the most capabilities and allow for the inclusion of inter-individual diversity of behavior on the person-level. They can therefore be potentially used for all applications of urban building energy models. However, due to the shortcomings discussed in section 4.1 they are currently not ready to model mixed-use scenarios. Instead of developing stochastic space-based models for additional building occupancy types, other options, including urban-scale activity-based multi-agent approaches could be considered. People interact with various buildings on a daily basis. Their activities relate to their presence in different spaces at the urban-scale and to their use of appliances. Their individual level of comfort and behavioral patterns govern the control actions towards building systems. Modeling people as agents in a multi-agent approach, therefore, 
seems to be a promising option to explore. Inspiration can be taken from earlier attempts to couple transportation and land use models to urban building energy simulations [117], from more general urban energy systems models [118], and from transport science itself.

The integration of transport simulation for modeling presence and activities of occupants in urban building energy simulation has been proposed for CitySim [117]. A multi-agent simulation platform (MATSim [119]) was intended to couple the simulation of individual journeys in the city and associated transport energy use to the building energy demand. The proposed platform consists of a synthetic population generator that assigned the agents with relevant socioeconomic parameters using a Monte Carlo method. The presence of occupants, specified by arrival time, location and departure time, would then be an output of the transport simulation's daily journeys of agents. For the generation of synthetic activity sequences an approach based on inhomogeneous Markov chain, e.g., [54, 120] was proposed.

The urban energy systems modeling toolkit SynCity [118, 121] contains an agent-based microsimulation agentactivity model to generate spatially and temporally varied patterns of resource-demand. The model simulates the daily activities of each citizen. It is implemented as a stochastic four-stage transportation model: at each time step, citizens select an activity, an activity provider (specific location), a transport mode, and a route. From the generated daily schedules of the agents, demands for electricity and heat are calculated. The necessary inputs to the model include the average activity profiles of the citizens. At the time of publication a fully detailed agent-activity model was under development. A simpler model was used to test for realistic resource demands. This model first assigns the estimated population to houses and employers within the city layout. Activity profiles for 16 different time periods (4 times per day, 2 types of day, and 2 seasons) and different socioeconomic characteristics control the performed activities of each citizen [118].

With agent-based approaches it is possible to model systems where agents influence each other, learn from their experiences and adapt their behavior. Agents' behavior is described by relatively simple rule sets. Interactions with other agents influence their behavior. These rule sets result in patterns, structures and behavior of the system as a whole. This self-organization and the emphasis on modeling the heterogeneity of agents in a population are two features that distinguish agent-based models from other techniques [122]. Agent-based approaches can reproduce the properties of classical stochastic occupant presence models based on Markov-chains [123]. They are used to create activity-chains of occupants in single buildings [124, 125]. Recent developments on the building-scale demonstrated the capabilities for incorporating different personality traits [126], agent learning [127], hierarchies among agents [128], goal-driven behavior [129] and behavioral changes over time [130]. These could all be valuable additions to scenario-based urban energy systems planning use cases.

\section{Conclusion}

Based on this review of current urban building energy models and their occupant behavior modeling approaches it can be concluded that occupant behavior is still considered at the individual building-scale and not at the urban-scale. The common approach to model mixed-use districts is to couple archetypical construction properties of buildings with standardized deterministic space-based occupant behavior models according to building occupancy type. This is currently also the only viable approach, as stochastic space-based and person-based occupant behavior models are only available for a limited number of building occupancy types.

Compared to deterministic approaches, models considering stochastic occupant behavior are able to generate more realistic spatiotemporal energy demand patterns at the district level. However, not all purposes of urban building energy models require such patterns. In general there should be a consistency in modeling approach and model purpose. For example an urban-scale building retrofit potential analysis evaluating overall annual energy savings most likely does not require a sophisticated stochastic occupant behavior model, whereas district energy system design, requiring realistic and robust peak demand estimations, would potentially profit from such models.

Given the capabilities of agent-based building-scale occupant behavior models and the prevalent usage of urbanscale multi-agent simulation approaches in transport science, the option for an agent-based urban-scale occupant behavior model for urban building energy simulations should be explored.

Such advanced urban-scale occupant behavior models could be capable of incorporating changes in population demographics, changes in behavior over time, and occupants' adaptation to economic or environmental changes. By adding the possibility to simulate scenarios of urban development under changing boundary conditions, such 
models would upgrade urban building energy models to tools for holistic urban planning and optimization of energy infrastructure.

\section{Acknowledgements}

This work was developed at the Future Cities Laboratory at the Singapore-ETH Centre, which was established collaboratively between ETH Zurich and Singapore's National Research Foundation (FI 370074016) under its Campus for Research Excellence and Technological Enterprise programme.

\section{References}

[1] United Nations Human Settlements Programme (UN-Habitat), Urbanization and Development: Emerging Futures, World Cities Report 2016, Technical Report, 2016.

[2] J. A. Fonseca, A. Schlueter, Integrated model for characterization of spatiotemporal building energy consumption patterns in neighborhoods and city districts, Applied Energy 142 (2015) 247-265.

[3] P. Caputo, G. Costa, S. Ferrari, A supporting method for defining energy strategies in the building sector at urban scale, Energy Policy 55 (2013) 261-270.

[4] C. F. Reinhart, C. Cerezo Davila, Urban building energy modeling - A review of a nascent field, Building and Environment 97 (2016) 196-202.

[5] C. Cerezo Davila, C. F. Reinhart, J. L. Bemis, Modeling Boston: A workflow for the efficient generation and maintenance of urban building energy models from existing geospatial datasets, Energy 117, Part 1 (2016) 237-250.

[6] L. G. Swan, V. I. Ugursal, Modeling of end-use energy consumption in the residential sector: A review of modeling techniques, Renewable and Sustainable Energy Reviews 13 (2009) 1819-1835.

[7] M. Kavgic, A. Mavrogianni, D. Mumovic, A. Summerfield, Z. Stevanovic, M. Djurovic-Petrovic, A review of bottom-up building stock models for energy consumption in the residential sector, Building and Environment 45 (2010) 1683-1697.

[8] W. Li, Y. Zhou, K. Cetin, J. Eom, Y. Wang, G. Chen, X. Zhang, Modeling urban building energy use: A review of modeling approaches and procedures, Energy (2017).

[9] M. Brøgger, K. B. Wittchen, Estimating the energy-saving potential in national building stocks - A methodology review, Renewable and Sustainable Energy Reviews 82 (2018) 1489-1496.

[10] J. Sokol, C. Cerezo Davila, C. F. Reinhart, Validation of a Bayesian-based method for defining residential archetypes in urban building energy models, Energy and Buildings 134 (2017) 11-24.

[11] Z. Shi, J. A. Fonseca, A. Schlueter, A review of simulation-based urban form generation and optimization for energy-driven urban design, Building and Environment 121 (2017) 119-129.

[12] L. Bourdic, S. Salat, Building energy models and assessment systems at the district and city scales: A review, Building Research \& Information 40 (2012) 518-526.

[13] W. Ma, S. Fang, G. Liu, R. Zhou, Modeling of district load forecasting for distributed energy system, Applied Energy 204 (2017) 181-205.

[14] D. Schmidt, H. Torio, Low Exergy Systems for High-Performance Buildings and Communities, International Solar Energy Society, 2011, pp. $1-7$.

[15] G. L. Authority, London Heat Network Manual, Technical Report, 2014.

[16] L. Frayssinet, L. Merlier, F. Kuznik, J.-L. Hubert, M. Milliez, J.-J. Roux, Modeling the heating and cooling energy demand of urban buildings at city scale, Renewable and Sustainable Energy Reviews (2017).

[17] L. A. Bollinger, R. Evins, HUES: A Holistic Urban Energy Simulation platform for effective model integration, in: Proceedings of International Conference CISBAT 2015 Future Buildings and Districts Sustainability from Nano to Urban Scale, LESO-PB, EPFL, 2015, pp. $841-846$.

[18] J. An, D. Yan, T. Hong, K. Sun, A novel stochastic modeling method to simulate cooling loads in residential districts, Applied Energy 206 (2017) 134-149.

[19] S. J. Quan, Q. Li, G. Augenbroe, J. Brown, P. P.-J. Yang, Urban Data and Building Energy Modeling: A GIS-Based Urban Building Energy Modeling System Using the Urban-EPC Engine, in: Planning Support Systems and Smart Cities, Lecture Notes in Geoinformation and Cartography, Springer, Cham, 2015, pp. 447-469.

[20] A. Horni, D. Scott, M. Balmer, K. Axhausen, Location Choice Modeling for Shopping and Leisure Activities with MATSim: Combining Microsimulation and Time Geography, Transportation Research Record: Journal of the Transportation Research Board 2135 (2009) 87-95.

[21] A. Grandjean, J. Adnot, G. Binet, A review and an analysis of the residential electric load curve models, Renewable and Sustainable Energy Reviews 16 (2012) 6539-6565.

[22] A. C. Menezes, A. Cripps, D. Bouchlaghem, R. Buswell, Predicted vs. actual energy performance of non-domestic buildings: Using post-occupancy evaluation data to reduce the performance gap, Applied Energy 97 (2012) 355-364.

[23] A. S. Silva, E. Ghisi, Uncertainty analysis of user behaviour and physical parameters in residential building performance simulation, Energy and Buildings 76 (2014) 381-391.

[24] G. Kazas, E. Fabrizio, M. Perino, Energy demand profile generation with detailed time resolution at an urban district scale: A reference building approach and case study, Applied Energy 193 (2017) 243-262.

[25] A. Mastrucci, P. Pérez-López, E. Benetto, U. Leopold, I. Blanc, Global sensitivity analysis as a support for the generation of simplified building stock energy models, Energy and Buildings 149 (2017) 368-383. 
[26] M. Mosteiro-Romero, J. A. Fonseca, A. Schlueter, Seasonal effects of input parameters in urban-scale building energy simulation, Energy Procedia 122 (2017) 433-438.

[27] Y. Ruan, J. Cao, F. Feng, Z. Li, The role of occupant behavior in low carbon oriented residential community planning: A case study in Qingdao, Energy and Buildings 139 (2017) 385-394.

[28] I. Richardson, M. Thomson, D. Infield, A high-resolution domestic building occupancy model for energy demand simulations, Energy and Buildings 40 (2008) 1560-1566.

[29] U. Wilke, F. Haldi, J.-L. Scartezzini, D. Robinson, A bottom-up stochastic model to predict building occupants' time-dependent activities, Building and Environment 60 (2013) 254-264.

[30] I. Gaetani, P.-J. Hoes, J. L. M. Hensen, Occupant behavior in building energy simulation: Towards a fit-for-purpose modeling strategy, Energy and Buildings 121 (2016) 188-204.

[31] D. Yan, W. O'Brien, T. Hong, X. Feng, H. Burak Gunay, F. Tahmasebi, A. Mahdavi, Occupant behavior modeling for building performance simulation: Current state and future challenges, Energy and Buildings 107 (2015) 264-278.

[32] T. Hong, S. C. Taylor-Lange, S. D'Oca, D. Yan, S. P. Corgnati, Advances in research and applications of energy-related occupant behavior in buildings, Energy and Buildings 116 (2016) 694-702.

[33] T. Hong, D. Yan, S. D'Oca, C.-f. Chen, Ten questions concerning occupant behavior in buildings: The big picture, Building and Environment 114 (2017) 518-530.

[34] T. Hong, Y. Chen, Z. Belafi, S. D'Oca, Occupant behavior models: A critical review of implementation and representation approaches in building performance simulation programs, Building Simulation (2017) 1-14.

[35] H. Lim, Z. J. Zhai, Review on stochastic modeling methods for building stock energy prediction, Building Simulation 10 (2017) 607-624.

[36] F. G. H. Koene, L. G. Bakker, D. Lanceta, S. Narmsara, S. M\&P, I. Fraunhofer, Simplified building model of districts, Proceedings of BauSIM (2014).

[37] D. Aerts, J. Minnen, I. Glorieux, I. Wouters, F. Descamps, A method for the identification and modelling of realistic domestic occupancy sequences for building energy demand simulations and peer comparison, Building and Environment 75 (2014) 67-78.

[38] R. Evins, K. Orehounig, V. Dorer, Variability between domestic buildings: The impact on energy use, Journal of Building Performance Simulation 9 (2016) 162-175.

[39] M. He, T. Lee, S. Taylor, S. K. Firth, K. J. Lomas, Coupling a stochastic occupancy model to EnergyPlus to predict hourly thermal demand of a neighbourhood, in: Proceedings of the 14th International Conference of the International Building Performance Simulation Association (BS2015), International Building Performance Simulation Association (IBPSA), Hyderabad, India, 2015, pp. pp. 2101 - 2108.

[40] B. Abushakra, J. S. Haberl, D. E. Claridge, Overview of Existing Literature on Diversity Factors and Schedules for Energy and Cooling Load Calculations (1093-RP), ASHRAE transactions 110 (1) (2004) 164-176.

[41] ASHRAE, Standard 90.1-2013 User's Manual, 2014.

[42] sia - swiss society of engineers and architects, SIA 2024 / 2006 D - Standard-Nutzungsbedingungen für Energie- und Gebäudetechnik', 2006.

[43] M. M. Armstrong, M. C. Swinton, H. Ribberink, I. Beausoleil-Morrison, J. Millette, Synthetically derived profiles for representing occupant-driven electric loads in Canadian housing, Journal of Building Performance Simulation 2 (2009) 15-30.

[44] T. Buso, V. Fabi, R. K. Andersen, S. P. Corgnati, Occupant behaviour and robustness of building design, Building and Environment 94 , Part 2 (2015) 694-703.

[45] A. Mahdavi, F. Tahmasebi, Predicting people's presence in buildings: An empirically based model performance analysis, Energy and Buildings 86 (2015) 349-355.

[46] J. A. Davis III, D. W. Nutter, Occupancy diversity factors for common university building types, Energy and Buildings 42 (2010) $1543-1551$.

[47] G. Happle, J. A. Fonseca, A. Schlueter, Effects of air infiltration modeling approaches in urban building energy demand forecasts, Energy Procedia 122 (2017) 283-288.

[48] M. A. López-Rodríguez, I. Santiago, D. Trillo-Montero, J. Torriti, A. Moreno-Munoz, Analysis and modeling of active occupancy of the residential sector in Spain: An indicator of residential electricity consumption, Energy Policy 62 (2013) 742-751

[49] J. Widén, A. M. Nilsson, E. Wäckelgård, A combined Markov-chain and bottom-up approach to modelling of domestic lighting demand, Energy and Buildings 41 (2009) 1001-1012.

[50] E. McKenna, M. Krawczynski, M. Thomson, Four-state domestic building occupancy model for energy demand simulations, Energy and Buildings 96 (2015) 30-39.

[51] J. Tanimoto, A. Hagishima, H. Sagara, Cooling load simulation considering actual variation of inhabitants' behavior for accurate estimation of urban maximum energy requirement, in: Building Simulation.

[52] J. Tanimoto, A. Hagishima, H. Sagara, A methodology for peak energy requirement considering actual variation of occupants' behavior schedules, Building and Environment 43 (2008) 610-619.

[53] J. Tanimoto, A. Hagishima, H. Sagara, Validation of methodology for utility demand prediction considering actual variations in inhabitant behaviour schedules, Journal of Building Performance Simulation 1 (2008) 31-42.

[54] J. Widén, M. Lundh, I. Vassileva, E. Dahlquist, K. Ellegård, E. Wäckelgård, Constructing load profiles for household electricity and hot water from time-use data-Modelling approach and validation, Energy and Buildings 41 (2009) 753-768.

[55] J. Widén, E. Wäckelgård, A high-resolution stochastic model of domestic activity patterns and electricity demand, Applied Energy 87 (2010) $1880-1892$.

[56] I. Richardson, M. Thomson, D. Infield, C. Clifford, Domestic electricity use: A high-resolution energy demand model, Energy and Buildings 42 (2010) 1878-1887

[57] D. Wang, C. C. Federspiel, F. Rubinstein, Modeling occupancy in single person offices, Energy and Buildings 37 (2005) $121-126$.

[58] J. Page, D. Robinson, N. Morel, J. L. Scartezzini, A generalised stochastic model for the simulation of occupant presence, Energy and Buildings 40 (2008) 83-98.

[59] C. Wang, D. Yan, Y. Jiang, A novel approach for building occupancy simulation, Building Simulation 4 (2011) $149-167$.

[60] F. Haldi, D. Robinson, Interactions with window openings by office occupants, Building and Environment 44 (2009) $2378-2395$.

[61] C. F. Reinhart, Lightswitch-2002: A model for manual and automated control of electric lighting and blinds, Solar Energy 77 (2004) 15-28. 
[62] S. D'Oca, V. Fabi, S. P. Corgnati, R. K. Andersen, Effect of thermostat and window opening occupant behavior models on energy use in homes, Building Simulation 7 (2014) 683-694.

[63] F. Tahmasebi, A. Mahdavi, The sensitivity of building performance simulation results to the choice of occupants' presence models: A case study, Journal of Building Performance Simulation 10 (2017) 625-635.

[64] S. Gilani, W. O’Brien, H. B. Gunay, Simulating occupants' impact on building energy performance at different spatial scales, Building and Environment 132 (2018) 327-337.

[65] Y. Chen, T. Hong, X. Luo, An agent-based stochastic Occupancy Simulator, Building Simulation 11 (2018) 37-49.

[66] Y. Chen, X. Liang, T. Hong, X. Luo, Simulation and visualization of energy-related occupant behavior in office buildings, Building Simulation 10 (2017) 785-798.

[67] W. O'Brien, H. B. Gunay, F. Tahmasebi, A. Mahdavi, A preliminary study of representing the inter-occupant diversity in occupant modelling, Journal of Building Performance Simulation 10 (2017) 509-526.

[68] F. Haldi, A probabilistic model to predict building occupants' diversity towards their interactions with the building envelope, in: Proceedings of BS2013: 13th Conference of International Building Performance Simulation Association, Chambéry, France, August 26-28 - 1478, Chambéry, France.

[69] F. Haldi, D. Calì, R. K. Andersen, M. Wesseling, D. Müller, Modelling diversity in building occupant behaviour: A novel statistical approach, Journal of Building Performance Simulation 10 (2017) 527-544.

[70] E. Fabrizio, V. Monetti, Methodologies and Advancements in the Calibration of Building Energy Models, Energies 8 (2015) $2548-2574$.

[71] C. Cerezo, J. Sokol, C. Reinhart, A. Al-Mumin, Three Methods for Characterizing Building Archetypes in Urban Energy Simulation. A Case Study in Kuwait City, in: Proceedings of BS2015: 14th Conference of International Building Performance Simulation Association, International Building Performance Simulation Association, Hyderabad, India, 2015.

[72] T. Suesser, T. Dogan, Campus Energy Model: Using a Semi-Automated Workflow to Build Spatially Resolved Campus Building Energy Models for Climate Change and Net-Zero Scenario Evaluation, in: Proceedings of the 15th IBPSA Conference, San Francisco, CA, USA7.

[73] R. Baetens, D. Saelens, Modelling uncertainty in district energy simulations by stochastic residential occupant behaviour, Journal of Building Performance Simulation 9 (2016) 431-447.

[74] B. Abushakra, A. Sreshthaputra, J. S. Haberl, D. E. Claridge, Compilation of Diversity Factors and Schedules for Energy and Cooling Load Calculations, ASHRAE Research Project 1093-RP, Final Report, Technical Report, 2001.

[75] K. Field, M. Deru, D. Studer, Using DOE Commercial Reference Buildings for Simulation Studies.

[76] M. Deru, K. Field, D. Studer, K. Benne, B. Griffith, P. Torcellini, B. Liu, M. Halverson, D. Winiarski, M. Rosenberg, US Department of Energy Commercial Reference Building Models of the National Building Stock, Technical Report, 2011.

[77] S. Heiple, D. J. Sailor, Using building energy simulation and geospatial modeling techniques to determine high resolution building sector energy consumption profiles, Energy and Buildings 40 (2008) 1426-1436.

[78] J. H. Kämpf, D. Robinson, Optimisation of urban energy demand using an evolutionary algorithm, in: Proceedings of the Eleventh International IBPSA Conference, pp. 668-673.

[79] D. Robinson, F. Haldi, J. Kämpf, P. Leroux, D. Perez, A. Rasheed, U. Wilke, CitySim: Comprehensive micro-simulation of resource flows for sustainable urban planning, in: Proc. Building Simulation, Citeseer, 2009, pp. 1614-1627.

[80] C. Reinhart, T. Dogan, J. A. Jakubiec, T. Rakha, A. Sang, Umi-an urban simulation environment for building energy use, daylighting and walkability, in: 13th Conference of International Building Performance Simulation Association, Chambery, France.

[81] K. Orehounig, G. Mavromatidis, R. Evins, V. Dorer, J. Carmeliet, Towards an energy sustainable community: An energy system analysis for a village in Switzerland, Energy and Buildings 84 (2014) 277-286.

[82] J. A. Fonseca, T.-A. Nguyen, A. Schlueter, F. Marechal, City Energy Analyst (CEA): Integrated framework for analysis and optimization of building energy systems in neighborhoods and city districts, Energy and Buildings 113 (2016) 202-226.

[83] J. A. FONSECA, A. WILLMANN, C. MOSER, M. STAUFFACHER, A. SCHLUETER, Assessing the environmental impact of future urban developments at neighborhood scale, in: Proceedings of International Conference CISBAT 2015 Future Buildings and Districts Sustainability from Nano to Urban Scale, LESO-PB, EPFL, 2015, pp. 457-462.

[84] P. Remmen, M. Lauster, M. Mans, M. Fuchs, T. Osterhage, D. Müller, TEASER: An open tool for urban energy modelling of building stocks, Journal of Building Performance Simulation 0 (2017) 1-15.

[85] P. Remmen, M. Lauster, M. Mans, T. Osterhage, D. Müller, CityGML Import and Export for Dynamic Building Performance Simulation in Modelica, in: Building Simulation and Optimization Conference (BSO16), Newcastle University, pp. 329-336.

[86] M. Lauster, M. Mans, P. Remmen, M. Fuchs, D. Mueller, Scalable Design-Driven Parameterization of Reduced Order Models using Archetype Buildings with TEASER, in: Conference Proceedings of Central European Symposium on Building Physics CESBP 2016 / BauSIM.

[87] Y. Chen, T. Hong, M. A. Piette, City-Scale Building Retrofit Analysis: A Case Study using CityBES.

[88] Y. Chen, T. Hong, M. A. Piette, Automatic generation and simulation of urban building energy models based on city datasets for city-scale building retrofit analysis, Applied Energy 205 (2017) 323-335.

[89] T. Hong, Y. Chen, S. H. Lee, M. A. Piette, CityBES: A web-based platform to support city-scale building energy efficiency, in: Urban Computing, San Francisco.

[90] P. Ellis, A Parametric Tool for Community-Scale Modeling, in: IBPSA-USA Journal, volume 6, Salt Lake City, UT.

[91] P. Nageler, G. Zahrer, R. Heimrath, T. Mach, F. Mauthner, I. Leusbrock, H. Schranzhofer, C. Hochenauer, Novel validated method for GIS based automated dynamic urban building energy simulations, Energy 139 (2017) 142-154.

[92] K. Ahmed, L. E. Ortiz, J. E. González, On the Spatio-Temporal End-User Energy Demands of a Dense Urban Environment, Journal of Solar Energy Engineering 139 (2017) 041005-041005-11.

[93] R. Wu, G. Mavromatidis, K. Orehounig, J. Carmeliet, Multiobjective optimisation of energy systems and building envelope retrofit in a residential community, Applied Energy 190 (2017) 634-649.

[94] R. Hendron, Building America Research Benchmark Definition, Technical Report NREL/TP-550-37529, National Renewable Energy Laboratory, Golden, Colorado, 2005.

[95] EQUA Simulation AB, IDA Indoor climate and energy, Avaiable: http://www. equa. se/en/ida-ice/.[Accessed: Dec 24, 2015] (2013). 
[96] Y. Chen, T. Hong, Impacts of building geometry modeling methods on the simulation results of urban building energy models, Applied Energy 215 (2018) 717-735.

[97] T. Hong, M. A. Piette, Y. Chen, S. H. Lee, S. C. Taylor-Lange, R. Zhang, K. Sun, P. Price, Commercial Building Energy Saver: An energy retrofit analysis toolkit, Applied Energy 159 (2015) 298-309.

[98] Y. Yamaguchi, Y. Shimoda, M. Mizuno, Development of district energy system simulation model based on detailed energy demand model, in: Proceeding of Eighth International IBPSA Conference, pp. 1443-1450.

[99] Y. Yamaguchi, Y. Shimoda, M. Mizuno, Proposal of a modeling approach considering urban form for evaluation of city level energy management, Energy and Buildings 39 (2007) 580-592.

[100] Y. Yamaguchi, Y. Shimoda, District-scale simulation for multi-purpose evaluation of urban energy systems, Journal of Building Performance Simulation 3 (2010) 289-305.

[101] Y. Yamaguchi, Y. Shimoda, T. Kitano, Reduction potential of operational carbon dioxide emission of Nakanoshima business/cultural area as a model for low-carbon districts in warm climates, Building and Environment 59 (2013) 187-202.

[102] V. Monetti, E. Fabrizio, M. Filippi, Impact of low investment strategies for space heating control: Application of thermostatic radiators valves to an old residential building, Energy and Buildings 95 (2015) 202-210.

[103] I. Richardson, M. Thomson, D. Infield, A. Delahunty, Domestic lighting: A high-resolution energy demand model, Energy and Buildings 41 (2009) 781-789.

[104] J. Schiefelbein, A. Javadi, M. Lauster, P. Remmen, R. Streblow, D. Müller, Development of a city information model to support data management and analysis of building energy systems within complex city districts, in: Proceedings of International Conference CISBAT 2015 Future Buildings and Districts Sustainability from Nano to Urban Scale, LESO-PB, EPFL, 2015, pp. 949-954.

[105] J. Schiefelbein, M. Diekerhof, A. Javadi, G. Bode, R. Streblow, D. Müller, A. Monti, Development of a Tool Chain For Complex City District Energy System Modeling and Simulation, in: Proceedings of BS2015, Hyderabad, India.

[106] Y. Yamaguchi, Y. Shimoda, T. Asai, M. Mizuno, Development of district energy supply system for CHP implementation, in: Proceedings Of, pp. 9-121.

[107] Y. Yamaguchi, Y. Shimoda, M. Mizuno, Transition to a sustainable urban energy system from a long-term perspective: Case study in a Japanese business district, Energy and Buildings 39 (2007) 1-12.

[108] Y. Shimoda, T. Fujii, T. Morikawa, M. Mizuno, Residential end-use energy simulation at city scale, Building and Environment 39 (2004) 959-967.

[109] Y. Shimoda, T. Fujii, T. Morikawa, M. Mizuno, Evaluation on Residential Energy Efficiency Programs Using the City-Scale End-Use Simulation Model, in: Proceedings of 2004 ACEEE Summer Study on Energy Efficiency in Buildings.

[110] Y. Shimoda, T. Asahi, A. Taniguchi, M. Mizuno, Evaluation of city-scale impact of residential energy conservation measures using the detailed end-use simulation model, Energy 32 (2007) 1617-1633.

[111] D. Robinson, N. Campbell, W. Gaiser, K. Kabel, A. Le-Mouel, N. Morel, J. Page, S. Stankovic, A. Stone, SUNtool - A new modelling paradigm for simulating and optimising urban sustainability, Solar Energy 81 (2007) 1196-1211.

[112] C. Wang, D. Yan, X. Ren, Modeling Individual's Light Switching Behavior to Understand Lighting Energy Use of Office Building, Energy Procedia 88 (2016) 781-787.

[113] X. Ren, D. Yan, C. Wang, Air-conditioning usage conditional probability model for residential buildings, Building and Environment 81 (2014) 172-182.

[114] D. Yan, J. Xia, W. Tang, F. Song, X. Zhang, Y. Jiang, DeST — An integrated building simulation toolkit Part I: Fundamentals, Building Simulation 1 (2008) 95-110.

[115] D. Aerts, Occupancy and Activity Modelling for Building Energy Demand Simulations, Comparative Feedback and Residential Electricity Demand Characterisation, Ph.D. thesis, 2015.

[116] K. Leidelmeijer, P. Van Grieken, Wonen En Energie - Stook- En Ventilatiegedrag van Huishoudens, Technical Report Rapportnummer: 86430, RIGO Research en Advies BV., 1011 AC Amsterdam, 2005.

[117] D. Robinson, U. Wilke, F. Haldi, Multi agent simulation of occupants' presence and behaviour, in: Proceedings of Building Simulation, pp. 2110-2117.

[118] J. Keirstead, N. Samsatli, N. Shah, SynCity: An integrated tool kit for urban energy systems modelling, Energy efficient cities: Assessment tools and benchmarking practices (2010) 21-42.

[119] A. Horni, The Multi-Agent Transport Simulation MATSim, Ubiquity Press, 2016.

[120] J. Widén, A. Molin, K. Ellegård, Models of domestic occupancy, activities and energy use based on time-use data: Deterministic and stochastic approaches with application to various building-related simulations, Journal of Building Performance Simulation 5 (2012) $27-44$.

[121] J. Keirstead, N. Shah, Urban Energy Systems: An Integrated Approach, Routledge, Abingdon, Oxon, 2013.

[122] C. M. Macal, M. J. North, Tutorial on agent-based modelling and simulation, Journal of Simulation 4 (2010) 151-162.

[123] C. Liao, Y. Lin, P. Barooah, Agent-based and graphical modelling of building occupancy, Journal of Building Performance Simulation 5 (2012) 5-25

[124] G. Zimmerman, Modeling and Simulation of Individual User Behavior for Building Performance Predictions, in: Proceedings of the 2007 Summer Computer Simulation Conference, SCSC '07, Society for Computer Simulation International, San Diego, CA, USA, 2007, pp. 913-920.

[125] V. Tabak, B. de Vries, Methods for the prediction of intermediate activities by office occupants, Building and Environment 45 (2010) 1366-1372.

[126] C. J. Andrews, D. Yi, U. Krogmann, J. A. Senick, R. E. Wener, Designing Buildings for Real Occupants: An Agent-Based Approach, IEEE Transactions on Systems, Man, and Cybernetics - Part A: Systems and Humans 41 (2011) 1077-1091.

[127] Y. S. Lee, A. M. Malkawi, Simulating multiple occupant behaviors in buildings: An agent-based modeling approach, Energy and Buildings 69 (2014) 407-416.

[128] A. Alfakara, B. Croxford, Using Agent-based Modelling to Simulate Occupants' Behaviours in Response to Summer Overheating, in: Proceedings of the Symposium on Simulation for Architecture \& Urban Design, SimAUD '14, Society for Computer Simulation International, 
San Diego, CA, USA, 2014, pp. 13:1-13:8.

[129] J. Langevin, J. Wen, P. L. Gurian, Simulating the human-building interaction: Development and validation of an agent-based model of office occupant behaviors, Building and Environment 88 (2015) 27-45.

[130] E. Azar, C. Menassa, Agent-Based Modeling of Occupants and Their Impact on Energy Use in Commercial Buildings, Journal of Computing in Civil Engineering 26 (2011) 506-518. 